\title{
"POCO LATÍN Y MENOS GRIEGO»: FEIJOO Y LAS LENGUAS CLÁSICAS
}

\section{"Small Latin and Less Greek»: Feijoo and Classical Languages}

\author{
Eduardo SAN JOSÉ VÁZQUEZ \\ Universidad de Oviedo \\ joseeduardo@uniovi.es \\ https://orcid.org/0000-0003-0398-532X
}

Fecha de recepción: 23/04/2020

Fecha de aceptación definitiva: 10/07/2020

RESUMEN: Este artículo examina la opinión de Benito Jerónimo Feijoo (1676-1764) acerca del cultivo del griego y del latín en la España del siglo XVIII. A través de textos del Teatro crítico universal (1726-1740) y de las Cartas eruditas y curiosas (1742-1760), se estudian, asimismo, las implicaciones y puesta en práctica de esas ideas, que cuestionaban la necesidad de estudiar el griego y la limitación del latín en la vida científica y cultural moderna. Puestas sobre el contexto del reformismo borbónico, se discute la influencia de un ideal casticista y nacionalista español en estas tesis, para concluir que el pragmatismo es el factor determinante en su preferencia de las lenguas vulgares.

Palabras clave: Benito Jerónimo Feijoo; Latín; Griego; Ilustración; Humanismo; Neoclasicismo.

ABSTRACT: This article examines Benito Jerónimo Feijoo's (1676-1764) opinion on the cultivation of Greek and Latin languages in the 18th Century Spain. By means of a selection of texts from his Teatro critico universal (1726-1740) and Cartas eruditas y curiosas (1742-1760), practical involvement of these ideas are also analysed, as they questioned the necessity of studying Greek and the limitation of Latin in modern scientific and cultural life. Placed on the context of Bourbon reformism, the 
article discusses the real influence of a Spanish purist, nationalistic ideal on these opinions, to conclude the essential role of pragmatism in his preference for vulgar languages.

Key words: Benito Jerónimo Feijoo; Latin; Greek; Enlightenment; Humanism; Neoclassicism.

And though thou hadst small Latin and less Greek, From thence to honour thee, I would not seek For names; but call forth thund'ring Aeschylus, Euripides and Sophocles to us;/[...] Leave thee alone for the comparison Of all that insolent Greece or haughty Rome Sent forth, or since did from their ashes come.

Ben Jonson, «To the Memory of my Beloved the Author, Mr. William Shakespeare»

Afirmaba Campomanes, en la semblanza póstuma que se le atribuye al frente de la edición de las obras conjuntas de Benito Jerónimo Feijoo (1765), que, en su ánimo de desterrar "errores populares» y «siguiendo el consejo del gran fray Luis de León", el benedictino había decidido escribir sus principales obras en lengua castellana y no en latín ${ }^{1}$. El gesto ayuda a singularizar a Feijoo en el panorama de la Ilustración temprana española, en la que el latín, pese a su decaimiento, seguía siendo la lengua de cultura, como sucedía en los novatores, Manuel Martí o Gregorio Mayans. No deja de ser un rasgo demótico en el retrato de uno de los formadores de la razón y el gusto del Dieciocho hispánico, que ampliaba así, con el número de lectores potenciales, la base social de su reformismo.

La decisión de ser un autor culto romance merecía todavía entonces, en la España de la primera mitad del siglo XviII en que Feijoo dio a la estampa la mayor parte de su obra, alguna justificación. Pero esa necesidad no tardaría en desaparecer. Al igual que haría tres décadas más tarde Campomanes en esa "Noticia de la vida y obra» de Feijoo pero con intención diversa, el clasicista y primer periodista español Juan Martínez Salafranca ya se creía en la obligación, que Lázaro Carreter tilda de "pedantesca" en 1736, de justificarse por escribir en castellano sus Memorias eruditas para la crítica de artes y ciencias, pues «son muy raros los que

1. [Campomanes, Pedro Rodríguez de]. «Noticia de la vida y obra del M. I. y R. P. M. Fr. Benito Jerónimo Feijoo [...]». En FeIjoo, Benito Jerónimo. Teatro crítico universal, o discursos varios en todo género de materias, para desengaño de errores comunes [...], tomo primero. Madrid: Imprenta Real de la Gaceta, 1765 , p. XI.

Para la atribución, circunstancias y significado de este elogio, vid. URZAINQUI, Inmaculada. "Campomanes y su "Noticia" de Feijoo". En Morales Raya, Remedios (coord.). Homenaje a la profesora María Dolores Tortosa Linde. Granada: Universidad de Granada, pp. 359-371. 
tienen cabal inteligencia» de la lengua latina ${ }^{2}$. Divergentes en la intención pero coincidentes en señalar la decisión de escribir en lengua vulgar, Campomanes y Salafranca traslucen un mismo escenario: el latín dejaba de ser lingua franca del conocimiento para convertirse en un obstáculo. La situación de abandono que hacía del latín una lengua poco menos que ignorada en el siglo XVIII apenas se vio compensada por el real decreto de 11 de septiembre de 1735 que, sintomáticamente, ordenaba el restablecimiento de la costumbre de hablar la lengua latina en los claustros de las universidades españolas ${ }^{3}$. Ajeno, sin embargo, a los círculos universitarios, iba fraguándose un movimiento intelectual contrario al latín como lengua de ciencia, con el espíritu de los nuevos tiempos; un impulso en el que destacan Feijoo y sus partidarios. Entre ellos, el médico Martín Martínez, quien, al decidirse por el castellano para su Medicina escéptica (1722-1725), renunciaba a la lengua facultativa y faltaba al voto hipocrático de no franquear la ciencia médica al vulgo, como justificaba en su prólogo al tomo primero:

No poca duda me costó elegir idioma en que escribir este libro. Proponíaseme, lo primero, que las materias graves y científicas (según la costumbre que hasta aquí ha habido entre los profesores) pedían escribirse en latín, como lenguaje serio y facultativo. Lo segundo, que los misterios del arte, como enseña Hipócrates, no se han de revelar a los profanos ${ }^{4}$.

El destino previsible de la lengua latina como reliquia se amortigua, no obstante, por la revitalización clasicista que conoció el siglo XVIII. En palabras de Lázaro Carreter, "el fetiche latino sigue obrando, en los principios del siglo, sobre casi todas las mentes ${ }^{5}$, y continuará manteniendo vivos su gusto y su autoridad a lo largo de la centuria. Sobreviviendo trabajosamente, el latín podría haber experimentado, pues, un retroceso mucho más acelerado del que sufrió en el Setecientos como consecuencia de los nuevos vientos de la modernidad y la revolución científica, si no hubiera sido por dos factores: por un lado, la Ilustración encontró afinidades en la Antigüedad, sobre todo allí donde el pensamiento ilustrado se convirtió en base de la ideología de Estado, la cual encontró en la paideia clásica una extensión pedagógica. Por otro lado, la época permitía relajar la censura eclesiástica del paganismo grecolatino, que hacía mucho tiempo que no amenazaba la Fe o las buenas costumbres. No en vano, la fuerza de la sospecha de heterodoxia recaía desde hacía más de dos centurias en la herejía protestante. Y, así, como

2. Juan Martínez Salafranca apud LÁZARO CARRETER, Fernando. Las ideas lingüísticas en España durante el siglo XVIII. Barcelona: Crítica, 1985, p. 163.

3. Vid. Aguilar PiÑal, Francisco. "Entre la escuela y la universidad: la enseñanza secundaria en el siglo XVIII". Revista de Educación, 1988, número extraordinario La educación en la Ilustración española, pp. 228-229.

4. Martínez, Martín. "Prólogo». En Medina sceptica y cirugía moderna [...], tomo primero. Madrid: [s. i.], 1722, [p. 4].

5. LÁzaro Carreter. Op. cit., p. 164. 
observa Luis Gil a partir de los datos de Iris Zavala, la frecuencia de los títulos griegos o latinos no deja de decaer en los Índices de la centuria hasta el último, en $1790^{6}$.

La confluencia de estos factores ayudó a la radicación de un nuevo neoclasicismo. Pues, la precisión es necesaria, el neohumanismo dieciochesco no obró una recuperación integral de la Antigüedad, desde los griegos a la invasión de los bárbaros, sino una selección clasicista. Con ella se descartaba, pues, todo lo sucedido desde Constantino hasta la Edad Media Latina incluida, a cambio de una Antigüedad "clásica» idealizada7. Así, allí donde el Renacimiento había visto en el humanismo un medio no de regresión arcaizante sino de superación de la escolástica anterior, el siglo XVIII operó de forma semejante respecto al neoescolasticismo tomístico.

Pero esta situación favorable a la tradición clásica seguía presentando en el siglo XVIII español matices muy importantes de resistencia al humanismo, como ha estudiado Luis Gil. La reticencia se hace muy elocuente, por ejemplo, en la carta que el humanista Manuel Martí dirige en 1722 al epigrafista italiano Escipión Maffei. En traducción de Luis Gil:

La naturaleza y la índole de los españoles es tal que da el nombre de piedad a derruir los monumentos de los paganos (así llaman a los romanos). Y consideran que con esta acción es como mejor se propician a Dios. ¡Qué errada piedad! Pero ¿Cómo podría suceder de otra manera en un reino sometido a una partida estólida e inculta de encapuchados? Desviarse una pulgada de los mandatos de los frailes lo tienen por impiedad. Veneran cualquier estupidez que digan como si fuese un oráculo emanado del trípode de Apolo. E hinchados de tan infame obediencia esos perfectos inútiles les amenazan con los suplicios del Infierno solo con poner la vista en alguna estatua antigua. Por eso, tan pronto como sale a la luz algún resto de ese tipo, le echan encima sus criminales manos, lo destrozan, lo hacen trizas ${ }^{8}$.

Esas resistencias, que Martí anota a los jesuitas, se harán más tenaces respecto a la enseñanza del griego, como se verá. No en vano, en el propio Feijoo debemos diferenciar la valoración y el cultivo que hacía de las lenguas griega y latina. Lo que no debe impedirnos distinguir las causas y los matices.

\section{FEIJOO Y LAS CULTURAS DE LA ANTIGÜEDAD}

En la conceptuación que Feijoo hace de las culturas antiguas debe notarse ante todo la falta de temor a llevar demasiado lejos, hasta la heterodoxia, su

6. Gil FernándeZ, Luis. Panorama social del humanismo español (1500-1800). Madrid: Alhambra, 1981, pp. 534-535.

7. CurTius, Ernst Robert. Literatura europea y Edad Media latina. Trads. Margit Frenk Alatorre y Antonio Alatorre. México: Fondo de Cultura Económica, 1955, p. 38.

8. Manuel Martí apud Gil FernándeZ. Op. cit., p. 498. 
admiración gentílica. El desdén amenazaba a los estudios clásicos más que las reticencias, procedentes casi siempre de la religión. La Iglesia, como se ha dicho, se sentía ya confiada de lo inocuo de estas influencias. Y renegar de la Antigüedad habría sido tanto como renunciar a la base aristotélica del tomismo. Más aún, como afirma Antonio Mestre desde Michel Dubuis, Feijoo populariza en España una actitud de valoración de la cultura profana que había aprendido de los benedictinos maurinos y de Pierre Mabillon en particular'. Sin temer por su ortodoxia, Feijoo expresaba abierta admiración por los logros de los antiguos:

¿Qué cosa hay en nuestro siglo que pueda competir los primores de la poética y oratoria del siglo de Augusto? ¿Qué plumas tan bien cortadas para la historia, como algunas de aquel tiempo? Retrocediendo dos o tres siglos más, y pasando de Italia a Grecia, se hallan en aquella región floreciendo en el más alto grado de perfección no solo la retórica, la historia y la poesía, mas también la pintura y la escultura (TC, IV, $12, \S$ II, 4) ${ }^{10}$.

Pero tampoco se quedó corto en condicionar la grandeza de sus civilizaciones: "Nadie ignora que los antiguos griegos y romanos eran muy hábiles para ciencias y artes. Con todo, ¿qué gente más fuera de camino en cuanto al culto? Adoraban dioses adúlteros, pérfidos, malignos» (TC, II, 15, § 7, 26) ${ }^{11}$. Aun así, la inocuidad de la religión, la mitología o la moral antiguas en este primer tercio del siglo XVIII se muestra tal que Feijoo no tiene problema en hacer una crítica meramente racionalista, sin entrar en la religiosa ni moral, de los Remedia amoris ovidianos, como estudia Vicente Cristóbal a propósito del discurso del tomo VII del Teatro crítico "Remedios del amor»"

Al valorar, pues, ambas civilizaciones, su admiración por la griega contrastaba con su consideración de la romana como una cultura sin originalidad. Cierto que la caracterización moral de Grecia no era favorable:

La Grecia, que hace representación muy singular en la historia antigua, así como nos ha dejado más noticia de sus sucesos, también la dejó de sus insultos. Fue más inexcusable en ella la corrupción de costumbres, por estar acompañada de la cultura de las letras. [...] La más fea obscenidad era tan transcendente en la Grecia que se ejercitaba sin pena y aun sin infamia. Aun muchachos ilustres se sujetaron

9. Mestre SANChIS, Antonio. "Reflexiones sobre el marco político-cultural de la obra del P. Feijoo". Bulletin Hispanique, 1989, 91: 2, p. 300.

10. Feijoo. "Resurrección de las artes y apología de los antiguos" (discurso 12). En Teatro crítico universal [...], tomo cuarto. Madrid: Viuda de Francisco del Hierro, 1730, p. 281.

11. FeIJOO. "Mapa intelectual y cotejo de naciones» (discurso 15). En Teatro crítico universal [...], tomo segundo. Madrid: Francisco del Hierro, 1728, p. 281.

12. Cristóbal, Vicente. "Los Remedia amoris de Ovidio, en la visión crítica del P. Feijoo". Cuadernos de Filología Clásica: Estudios Latinos, 1991, 1, pp. 233-240. 
sin vergüenza a este oprobio, y no faltaron filósofos que le autorizaron con su patrocinio (TC, II, 7, § V, 24) $)^{13}$.

Pero si sus faltas atentaban contra la virtud o las costumbres, asistía a Grecia al menos el descargo de su impulso civilizador, del que Roma era solo émula. Para Luis Rodríguez Ennes, quien estudia la "romanofobia» de Feijoo y Martín Sarmiento y su pervivencia hasta Ortega y Gasset, "participa Feijoo de un movimiento cultural que se inicia en su tiempo y que se mantiene todavía en pleno siglo diecinueve por Hegel de hipervalorar lo helénico como modo de justificar la ausencia de originalidad de la cultura latina ${ }^{14}$. Así, a Roma le anotaba aquellas mismas faltas y le añadía los dicterios de la tiranía y el abuso.

Son conocidas las palabras de Feijoo en el discurso "Glorias de España", primera parte, del tomo IV del Teatro crítico (1730):

Siempre que me vienen a la memoria las conquistas con que se engrandeció el imperio romano y el aplauso con que el mundo clamorea, admirando al mismo tiempo aquella república como la norma de todas en cuanto a las virtudes políticas y militares, no puedo menos de lastimarme de la debilidad del juicio humano, que, dejándose fácilmente deslumbrar de un falso resplandor, apenas en materia alguna acierta a mirar con ojos fijos en la verdad. ¿Qué fue la república romana? Una gavilla de ladrones que, engrosándose más y más cada día, empezó robando ganados, prosiguió robando poblaciones y acabó robando reinos.

[...] Es verdad que conquistaron los romanos el mundo. ¿Pero cómo? Del mismo modo que conquistaron a España. Usando de la perfidia, del dolo, de la alevosía, siempre que no podían lograr con mejores artes la ventaja.

[...] Yo estoy tan lejos de asentir a las ventajas del valor romano sobre las demás naciones del mundo que vivo persuadido a que cualquiera de estas hubiera hecho todo lo que hicieron los romanos, puesta en las mismas circunstancias. Parecerá una extraña paradoja si digo que la conquista del orbe, en la forma que los romanos la lograron, fue una cosa facilísima que solo pedía de parte de los ejecutores ambición y tiempo; pero no manos ni valor (TC, IV, 13, § VIII, 29, 31; § IX, 33) ${ }^{15}$.

En su recorrido por la historia política romana, Feijoo solo salva a los tres emperadores hispanos: Trajano, Adriano y Teodosio. Y aun este será un elogio remiso; por ejemplo, en su condena de los vicios de Trajano o de las creencias y costumbres de Adriano, al señalarlo como «loco» por el culto que instituyó al bello

13. FeIJoo. "Senectud moral del género humano" (discurso 7). En Teatro crítico universal [...], tomo segundo, p. 168.

14. RODRÍGUEZ ENNES, Luis. "Sarmiento, Feijoo y Ortega: una explicación al origen y persistencia histórica de la romanofobia». Revista General de Derecho Romano, 2013, 21, p. 9.

15. FeIjoO. "Glorias de España. Parte primera" (discurso 13). En Teatro crítico universal [...], tomo cuarto. Madrid: Viuda de Francisco del Hierro, 1730, pp. 332-335. 
Antínoo, a cuya memoria erigió aras y templos (TC, VI, 1, Paradoja XII, 118) ${ }^{16}$. Como apunta Robert Ricard, la incorporación que Feijoo hace de la Antigüedad romana a la raíz del relato de la nacionalidad hispánica habla en principio de su alta estimación, tanto de los escritores hispanolatinos -Séneca, Pomponio Mela, Columela, Quintiliano, Lucano, Marcial, etc.- como de los emperadores, y se traduciría en la costumbre de escribir a veces el nombre de España con una "H» inicial, como la de la Hispania romana ${ }^{17}$. Y, sin embargo, de los tres emperadores hispanorromanos Feijoo solo hará elogio, y no incondicional, del cristiano Teodosio, lo que nos aclara su criterio, orientado menos por la nacionalidad que por la religión ${ }^{18}$.

En el tomo III de las Cartas eruditas (1750), continuará ostentando el mismo desprecio de la civilización romana, la cual rebaja entre las paganas, para terminar censurando a "los infinitos admiradores que hay de la política y generosidad de los romanos, en cuyo número no entro yo, ni entraré jamás» (CE, III, 17, 15) ${ }^{19}$.

\section{FEIJOO Y LAS LENGUAS ANTIGUAS}

En cambio, al valorar las lenguas antiguas la estimación se invierte; guiada, no obstante, por un eminente sentido práctico. Así, en las cartas 23 y 24 del tomo V de las Cartas eruditas (1760), "Disuade a un amigo suyo el autor el estudio de la lengua griega y le persuade el de la francesa» $y$ "Reflexiones que sirven a explicar y determinar con más precisión el intento de la inmediata carta antecedente», Feijoo se manifiesta por el aprendizaje de las lenguas modernas, especialmente la francesa, en detrimento de las antiguas:

Para todo género de literatura entre todas las lenguas, la inteligencia que más nos importa es la de la francesa. La razón es porque todas las ciencias y artes útiles hablan y escriben en francés, o el francés habla y escribe todas las ciencias y artes útiles (CE, V, 23, § VII, 35) ${ }^{20}$.

16. FeIjoo. "Paradojas políticas y morales» (discurso 1). En Teatro crítico universal [...], tomo sexto. Madrid: Herederos de Francisco del Hierro, 1734, p. 56.

17. RICARD, Robert. "Feijoo et les empereurs romains d'Espagne». En VV. AA. Les empereurs romains d'Espagne (Actes du Colloque International, Madrid 31 mars-6 avril 1964). Paris: Éditions du Centre National de la Recherche Scientifique, 1965, p. 298.

18. Como destaca RICARD, Feijoo aprovecha también a Teodosio para manifestar su antimaquiavelismo y antiabsolutismo cristianos: «Il s'élève [...] contre les théoriciens de l'absolutisme, auxquels il reproche ailleurs, et avec des expressions trés fortes, de conférer au souverain un caractère surnaturel et divin". Ibid., p. 297.

19. FeIjOO. "Cómo trata el Demonio a los suyos" (carta 17). En Cartas eruditas y curiosas [...], tomo tercero. Madrid: Herederos de Francisco del Hierro, 1750, p. 192.

20. Feijoo. "Disuade a un amigo suyo el autor el estudio de la lengua griega, y le persuade el de la francesa" (carta 23). En Cartas eruditas y curiosas [...], tomo quinto. Madrid: Joaquín Ibarra, 1760 , p. 189. 
En ningún caso corregirá sus opiniones sobre las dos grandes culturas antiguas, y la lengua helénica se le hará mucho más extensa, elocuente, bella y melódica que la latina. Decía ya en el discurso "Mérito y fortuna de Aristóteles y de sus escritos», del tomo IV del Teatro crítico: «La lengua griega es sin comparación más copiosa que la latina. Cuando, pues, uno que es perito en las dos lenguas griega y latina quiere traducir algún escrito de aquella a esta, necesariamente encuentra muchas veces el tropiezo de no hallar voz latina equivalente a la griega» (TC, IV, $7, \S \mathrm{XVI}, 55)^{21}$.

De ambas lenguas, en cambio, confiesa no saber griego. Su conocimiento de las obras helénicas se basaba en traducciones latinas, castellanas o francesas. Un neto espíritu práctico le provoca ahora esta curiosa paradoja: en la valoración de las lenguas, como en la de las culturas, triunfa la griega. En su cultivo, prevalece sin duda la latina. Escribe al inicio de la citada carta 23 del último tomo de las Eruditas:

Nada sé de la lengua griega; y si un tiempo supe algo, ese algo no era más que un casi nada. Tuve, sí, muchos años ha, alguna inclinación a aprenderla, pero la resistí por tres motivos. El primero fue parecerme que el tiempo que expendiese en esa tarea podría emplearse en otros estudios más útiles. El segundo, considerar que sin más escuela que la de los libros no podría adquirir sino una inteligencia muy imperfecta de la lengua. Apenas se puede lograr ni aun mediano aprovechamiento en estudio alguno sin que poco o mucho intervenga en la enseñanza voz viva de maestro. Especialmente para adquirir cualquiera idioma, es esta totalmente inexcusable; porque en la pronunciación propia de cada uno no se puede entrar enteramente por la lectura. Este no es negocio de los ojos, sino de los oídos.

[...] Digo, pues, señor, que el tercer motivo por que me retiré del estudio de esta lengua fue considerarla de muy corta importancia in re literaria $(\mathrm{CE}, \mathrm{V}, 23 \text {, § I, } 1 \text { y } 4)^{22}$.

Como sabe escandaloso sostener una afirmación semejante, pasa a explicarla. Se trata de un pensamiento utilitarista y no estético: aun concediendo que los poetas griegos adelantasen en mucho a sus epígonos latinos (Homero a Virgilio, Píndaro a Horacio, Anacreonte a Ovidio, citando a los tres grandes autores del clasicismo romano), nada queda de ellos sin traducir al latín o a la mayoría de lenguas vulgares, por lo que, aun prescindiendo del goce estético, sus enseñanzas son indistintas en una traducción asequible: «¿De qué nos sirven esos mejores poetas? ¿Qué verdades nos enseñan que no nos hagan presentes los autores latinos?» (CE, V, 23, § II, 11) $)^{23}$.

Al fin, emparenta a los grecizantes actuales con los alquimistas. La jactanciosa posesión del griego, como una vana piedra filosofal:

21. FeIjOO. "Mérito y fortuna de Aristóteles y de sus escritos" (discurso 7). En Teatro crítico universal [...], tomo cuarto. Madrid: Viuda de Francisco del Hierro, 1730, p. 157.

22. Feijoo. "Disuade a un amigo suyo el autor el estudio de la lengua griega...", pp. 374-376.

23. Ibid., p. 379. 
El magnífico título de fuente de toda erudición, aplicado a la lengua griega, puede pasar por un secreto literario análogo a los físicos que he dicho, pues en él se ofrece dar una gran extensión a la ciencia como en aquellos aumentar la riqueza o alargar la vida; y es tan engañoso este como aquellos, pues, en vez de aumentar la erudición, la acorta, como los otros la vida y la hacienda. La razón es porque la aplicación a la lengua griega ocupa el tiempo que se pudiera emplear en otro estudio más útil y que adornase el alma de muchas importantes noticias literarias que no franquea la lengua griega. Fue este estudio un tiempo utilísimo, en cuanto nos produjo la traducción de las obras de algunos o de todos los buenos autores griegos. Ahora la Grecia no puede darnos cosa de provecho; porque lo bueno, que es lo antiguo, ha mucho tiempo que está dado (CE, V, 23, § V, 26) $)^{24}$.

Consciente de que su opinión puede sonar violenta y opuesta a los principios de la buena crítica, que prescribe la comprobación directa de documentos y fuentes, la carta siguiente, postrera del tomo y, por lo tanto, el último texto impreso de la carrera literaria de Feijoo, se dirige a justificar la anterior, negando haber propuesto la erradicación del estudio del griego en España, sino solo manifestado "la displicencia con que miro la superioridad que se atribuyen los grecizantes sobre los demás estudiosos que carecen de esta especie de literatura» (CE, V, 24, 7) ${ }^{25}$. $\mathrm{Y}$, así, tras ponderar el griego como una «lengua digna del aprecio de todos los amantes de las letras» (CE, V, 24, 8) ${ }^{26}$, manifiesta únicamente que «lo de apreciarla como fuente de toda erudición es un hipérbole excesivo o elogio entusiástico de que usan los aficionados a ella para hacer más plausible su aplicación» (CE, V, 24, $20)^{27}$.

La controversia venía a coincidir con una revaluación histórica del griego. Como observa Luis Gil desde María Rosa Lida de Malkiel, «la Ilustración española da un giro radical a la valoración del griego como instrumento de cultura. También aquí tuvo lugar, como en Alemania, Francia e Inglaterra, un redescubrimiento de Grecia ${ }^{28}$. De ahí que la opinión de Feijoo pasara a verse entre algunos como insensata; y así Mayans, aun concediendo alguna razón al pesimismo de Feijoo, escribe al médico Antonio Capdevila en diciembre de 1760, al poco de este último tomo de las Cartas eruditas: "Tenga Vm. por tema de los delirios de Feijoo la preferencia de la lengua francesa a la griega ${ }^{29}$. Y, meses después, Lanz de Casafonda hacía hablar así a los personajes de sus Diálogos de Chindulza (1761):

24. Ibid., pp. 385-386.

25. Feijoo. "Reflexiones que sirven a explicar y determinar con más precisión el intento de la inmediata carta antecedente, en la que se sigue última” (carta 24). En Cartas eruditas y curiosas [...], tomo quinto. Madrid: Joaquín Ibarra, 1760, p. 401.

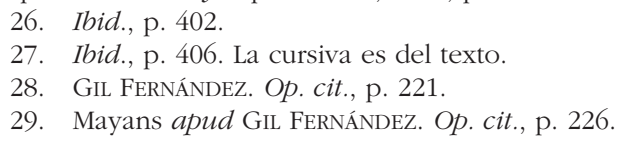


BARTOLI. [...] ¿Querrás creer que, habiéndole escrito [a Feijoo] un caballero que se había aplicado a aprender la lengua griega [...], se pone a hacer una invectiva contra los que saben el griego, y aconseja al caballero que deje el estudio de la tal lengua, porque es poca o ninguna la utilidad que se saca? Y entre las muchas fútiles y sofísticas razones que da es que todo lo que hay de bueno está ya traducido.

SABelli. [...] Me admira que un hombre tan docto, y que tiene un Real Privilegio para no ser impugnado, haga como burla de los que se aplican al griego y diga que no es necesario su estudio. Verdaderamente es grande el daño que puede causar la opinión de este padre, que es venerado por oráculo en toda España y en las Indias ${ }^{30}$.

Pero, en general, el redescubrimiento del griego se dio en proporciones modestas y ajustadas a la mediocridad cultural del país; y así, por ejemplo, descubrimos a Feijoo en la misma idea con que el jesuita Antonio Codorniu, perteneciente al círculo extenso del benedictino, ataca a los malos críticos que habían llegado a infestar el siglo, y defiende que un exceso de erudición es soberbia dañina y nada añaden la lengua hebrea o griega si sus lecciones vienen comprendidas suficientemente en la latina, como tampoco san Gregorio Magno supo ni se preocupó de saber griego, según reconocía en su Epístola a Eusebio (lib. 3, cap. 33): "Nos nec græce novimus, nec aliquod opus græce scripsimus " ${ }^{31}$. Al identificar las Dolencias de la crítica, obra que dedicaba en 1760 a Feijoo, Codorniu no podía desconocer que el benedictino compartía el dictamen. Y así, frente a lo que Melchor Cano censuraba de los primeros escolásticos, que no sabían hebreo ni griego, remata Codorniu a los malos críticos: «Sean tan útiles como se quiera las dichas lenguas, pero nunca serán tan necesarias como pretenden aquellos críticos, que para graduar a uno de buen teólogo parece que antes le examinarían de las lenguas griega y hebrea que de la doctrina cristiana ". $^{32}$.

El prejuicio utilitario no fue, pues, exclusivo de Feijoo. Si observamos la misión helenística que se impusiera Campomanes, apasionado humanista, una tarea ardua incluso para el inmenso poder político que encarnó, descubriremos la suma de sus frustraciones por tratar de animar el cultivo del griego en España. En la ya referida "Noticia de la vida y obras" de Feijoo en 1765, Campomanes hallaba un único motivo de reproche al benedictino, fallecido el año anterior, abonando con ello más si cabe la hipótesis de su autoría encubierta. Encontró, así, causa para aludir a su opinión sobre la lengua griega:

En dos cartas de este tomo se muestra el P. Feijoo nada afecto al estudio de la lengua griega, prefiriendo el de la francesa. Esta última entre nosotros es tan fácil

30. LANZ DE CASAFOnda, Manuel. Diálogos de Chindulza. (Sobre el estado de la cultura española en el reinado del Fernando VI). Oviedo: Cátedra Feijoo/Universidad de Oviedo, 1972, pp. 44, 46.

31. Gregorio Magno apud CoDorniu, Antonio. Dolencias de la crítica, que para precaución de la estudiosa juventud expone a la docta madura edad, y dirige al muy ilustre señor don Fr. Benito Gerónimo Feyjoo [...]. Gerona: Antonio Oliva, 1760, p. 6.

32. Ibid., p. 8. 
de adquirir que apenas hay sujeto de mediana educación que no la entienda. Nada puede embarazar su estudio el unir algunas nociones del griego a lo menos.

Francisco Valles debió a este conocimiento sus progresos en la doctrina de Hipócrates; y hoy lo acredita el doctor D. Andrés Piquer.

Martín Martínez de Cantalapiedra ¿cómo podría haber escrito su tratado sobre interpretar la Escritura sin este auxilio?

Benito Arias Montano sobresalió a todos los de su tiempo por el conocimiento del griego y del hebreo. Él hizo familiar el estudio fundamental de las Sagradas Escrituras en toda la Europa.

¿Qué habría adelantado D. Antonio Agustín en sus obras civiles y canónicas sin el consumado estudio del idioma griego?

¿Por cuánto número de años no han estado ocultos los manuscritos árabes del Escorial, hasta que D. Miguel Casiri, de la Academia de la Historia, intérprete de S. M. para la lengua árabe, nos ha formado el catálogo?

Lo mismo sucede con los manuscritos griegos y hebreos que sin uso han estado ocultos en la misma biblioteca, hasta que el doctor D. Francisco Pérez Bayer, con el auxilio de ambos idiomas, se ha dedicado a publicarles.

D. Juan de Iriarte, bibliotecario de S. M., ha hecho un excelente catálogo de los manuscritos griegos existentes en la Biblioteca del Rey por su pericia en esta lengua.

¿Qué no se debe al deán de Alicante D. Manuel Martí y al diligente D. Gregorio Mayans por sus estudios en la buena literatura y cultivo de las más puras fuentes de la elocuencia griega y romana? ${ }^{33}$.

Estudiando la labor humanística de este helenista en el poder, como él lo define, Luis Gil anota los escrúpulos antihelénicos a lo largo de la dificultosa historia del humanismo español; resistencias identificables, por ejemplo, en la magra dotación de puestos de enseñanza o en los datos de publicación de manuales y gramáticas, más humillantes aún que los del latín. Una situación que se preocuparía de resolver el poderoso fiscal del Consejo, para terminar dándose contra las viejas dificultades, pues la restauración en España de los estudios helénicos, pendiente con la subida al trono de Carlos III, aún persistiría hasta la llegada de Carlos IV, con la dotación en 1796 de la cátedra de la Universidad Complutense. En la Universidad de Oviedo, por ejemplo, la materia no se impartió en todo el siglo, pese a que el nuevo plan de estudios remitido por Campomanes en 1774 disponía la habilitación de una cátedra, lo que conllevó las protestas del claustro ${ }^{34}$. La situación persistió más allá incluso de ver realizado el viejo propósito del adelantamiento

33. [CAMPOMANES]. Op. cit., pp. XVII-XVIII.

34. Gil Fernández. Campomanes, un helenista en el poder. Madrid: Fundación Universitaria Española, 1976, p. 53. 
de los modernos studia bumanitatis con la retirada de la exclusividad pedagógica jesuítica, que se hizo efectiva con la expulsión de la Compañía en $1767^{35}$.

Tiempo atrás, examinando el progreso de las ciencias y las artes en España, al justificarse Feijoo por no haberse metido a expositor de la Sagrada Escritura a causa de no dominar las cuatro lenguas necesarias, "esto es, la griega, la hebrea, la siriaca y aun la arábiga", denunciaba la falta de buenos maestros en España, y traía a colación a cierto ministro helenófilo:

¿Y cómo se han de aprehender estas lenguas con perfección en España? No lo sé. Sé que no ha muchos años que hubo en cierta universidad nuestra un catedrático de griego de quien un ministro muy aficionado al mismo idioma decía que no tenía inteligencia alguna de él. Es verdad que el catedrático le pagaba al ministro en la misma moneda. Y yo creo que uno y otro tendrían razón (CE, III, 31, 59) ${ }^{36}$.

En esa fecha de 1750 Feijoo no podía aludir todavía en tal calidad al juriconsulto asturiano, quien recibiría su primer ministerio una década más tarde, ni probablemente hubiera querido referirse en tales términos a su admirador y futuro favorecedor en la corte ${ }^{37}$. El peso de la cita cae, de todos modos, sobre la ausencia de buenos maestros helenistas en España, argumento sobre el que vuelve y en el que hará estribar la razón de su desdén por el aprendizaje del griego.

La situación era tal que el propio Mayans manifiesta que nunca llegó a dominar el griego por falta de maestro competente de los estudios trilingües, como ya se quejaba en carta al padre Rávago de 1748:

Pues la lengua hebrea ¿quién no sabe que murió con el doctor Benito Arias Montano, y la griega, pocos años ha, con don Manuel Martí, deán de Alicante? Pues sin el debido conocimiento de las lenguas eruditas, ¿quién creerá que se pueden entender bien los libros más eruditos escritos en ellas? ¿Cómo se podrá saber originalmente? ¿Cómo se escribirá contra los herejes versados en ellas? ${ }^{38}$.

O con el mismo pesimismo que tiempo después seguiría protestando, según se ha visto arriba, a Antonio Capdevila:

En cuanto a la lengua griega, el Sr. Pluer ha hablado de mí como apasionado. Vm. crea que en España, después que faltó D. Manuel Martí, no hay quien la sepa. Si

35. Ibid., pp. 47-48.

36. FEIJOO. "Sobre el adelantamiento de ciencias y artes en España. Y apología de los escritos del autor» (carta 31). En Cartas eruditas y curiosas [...], tomo tercero. Madrid: Herederos de Francisco del Hierro, 1750, pp. 407-408.

37. También es posible que Feijoo utilice aquí la voz ministro con el sentido que emplea en otras ocasiones, como 'juez o ministro de justicia', segunda acepción en el Diccionario de autoridades. Así en el discurso «La balanza de Astrea, o recta administración de la justicia»(TC, III, 11).

38. Gregorio Mayans apud Gil FERnández. Op. cit., pp. 219-220. 
con dificultad hallará Vm. tres o cuatro que sepan latín, ¿cómo han de saber griego? A nadie crea $\mathrm{Vm}$. en este asunto ${ }^{39}$.

Idéntica excusa es la que da el personaje de fray Gerundio para sus limitadas erudiciones, lo que sirve a José Francisco de Isla, autor afecto a Feijoo y satirizante de los mismos males retóricos y pedagógicos que anotaba el benedictino, para ridiculizar la pretensión de alcanzar por esa vía cualquier utilidad o mérito. Se justificaba el protagonista:

No podemos menos de lamentar segunda vez nuestra desgracia en no haber tenido quien en nuestra adolescencia nos enseñase por lo menos la lengua griega y hebrea, que no solo nos servirían de mucho en esta ocasión, sino en otras de mucha mayor importancia. Y aunque oímos condenar a muchos que parecen personas este género de estudio como inútil o como menos necesario, a nosotros nos hace más fuerza el ejemplo de los mayores hombres de todos los siglos que el particular dictamen de los que en ningún siglo tienen traza de ser muy hombres ${ }^{40}$.

Es por eso que en la explicación de prioridades de Feijoo los derechos de la curiosidad humanística se subordinan a una idea pragmática de las lenguas, tanto al valorar los idiomas modernos frente a las lenguas muertas como al ponderar su evolución adaptativa, ajeno, pues, a preocupaciones puristas. Feijoo, a quien Menéndez Pelayo calificaría como "temerario innovador de la lengua "41, reitera a lo largo de su obra una concepción práctica y comunicativa de la lengua, ya sea mostrándose opuesto al ideal de pureza etimológica, en su defensa de las voces extranjeras en la lengua española -expresada en el discurso "Paralelo de las lenguas castellana y francesa" del tomo primero del Teatro crítico (1726) y reafirmada en la carta "Defiende el autor el uso que hace de algunas voces o peregrinas o nuevas en el idioma castellano", del tomo I de las Eruditas, de 1742-; ya sea juzgando con escepticismo la originalidad de la lengua latina, que suponía derivada de dialectos griegos, pues «es sabido que la lengua latina, cual hoy la tenemos en dieciocho o veinte siglos a esta parte, no es lengua original, sino derivada de la griega, especialmente del dialecto eolio, con la mezcla de varias voces oscas, etruscas y de otros pueblos antiguos de Italia» (TC, IV, 3, § IX, 25) ${ }^{42}$.

El utilitarismo de Feijoo no se limitaba, sin embargo, a preterir el griego frente al latín. También respecto a la lengua latina expresaba el mismo orden de opiniones, en el que pareceríamos descubrir a un continuador de los prejuicios antihumanistas que desde el Renacimiento dividían en dos a los impuestos en latines:

39. Ibid., p. 225.

40. IsLa, José Francisco de. Historia del famoso predicador fray Gerundio de Campazas, alias Zotes. Ed. Joaquín Álvarez Barrientos. Barcelona: Planeta, 1991, p. 699.

41. MenÉndez Pelayo, Marcelino. Historia de las ideas estéticas, III: El siglo XVIII. Madrid: CSIC, 1967, p. 111.

42. FeIjoo. "Lámparas inextinguibles» (discurso 3). En Teatro crítico universal [...], tomo cuarto. Madrid: Viuda de Francisco del Hierro, 1730, p. 55. 
los letrados y los gramáticos. Prósperos juristas y prácticos hombres de leyes, en el primer caso; dómines momificados, pobres preceptores y vanos eruditos, en el segundo ${ }^{43}$.

Como vemos a través del Fray Gerundio, a menudo, y con tal de no parecer un pobre canónigo en romance, el latín era una plaga al servicio de la bachillería, una jerigonza que, «aunque parece suena a latín, es de una latinidad monstruosa, bárbara y salvaje. Pero, con licencia de su mala condición, yo le digo claritamente y en sus barbas que no sabe cuál es su latín derecho, y que se conoce que en su vida ha saludado los cristus" ${ }^{44}$. Y como "la admiración no tiene por objeto lo bueno, sino lo raro", se trataba de un latín de escasa noticia bíblica y calepínica, deformado, estrambótico, hecho para su admiración como forzosamente ininteligible: "Y si no lo entendieren los lectores, que aprendan otro oficio, porque esa no es culpa del autor, el cual, cuando se pone a escribir en latín, no ha de gastar un latín que le entienda cualquier reminimista ${ }^{45}$. Algo que el narrador da en llamar, siguiendo posiblemente el ejemplo de la culta latiniparla que satirizaba Quevedo en su opúsculo antigongorino (1624), un "estilo cultilatinorrumbático» ${ }^{46}$. En esa crítica del culteranismo sermonístico que infestaba los púlpitos españoles, Isla y Feijoo encontraban un blanco común: Francisco Soto Marne, autor de un Florilegio sacro (1738), a quien Feijoo apelaba Floriloco y que más tarde se convertiría en el último gran contradictor de Feijoo ${ }^{47}$.

El benedictino se quejaba también del recurso al latín como timbre de autoridad. Particularmente en el ejercicio de las disciplinas liberales, Feijoo señalaba el prestigio obtenido así a bajo costo. Los albores de su carrera habían estado marcados, como se ha visto, por la polémica médica, que también fue una polémica castellanista, protagonizada por su amigo Martín Martínez. Este abría su Medicina escéptica con una sátira del médico dogmático o escolástico, "ganando vida entre la gente de montón con media docena de términos rimbombantes y de ruido» ${ }^{48}$.

43. Para la estimación social de las lenguas clásicas y del humanista en la España de los Siglos de Oro, vid. Gil Fernández. Op. cit., capítulo «Letrados, gramáticos, humanistas», pp. 231-254. La sombra de esa dicotomía se alarga en el siglo XVIII, como también la necesidad de justificarse del verdadero humanismo. Así, en su edición de los textos de los jesuitas expulsos novohispanos cultivadores del humanismo, Gabriel MÉNDEZ PlanCARTE se ve obligado a diferenciar: "Un dómine enjuto de carnes y de mollera, fosilizado en la árida disección de lenguas muertas [...]. El humanista auténtico no es eso. El humanista auténtico es el hombre que, mediante la asimilación de los más altos valores de la humanidad precristiana y su síntesis vital con los valores supremos del cristianismo, llega a realizar en sí un tipo superior de "hombre" en el que la esencia humana logra florecimiento y plenitud" "Introducción". En VV. AA. Humanistas del siglo XVIII. Introd. y selecc. Gabriel Méndez Plancarte. México: Ediciones de la UNAM, 1941, p. VIII).

44. IsLA. Op. cit., p. 63

45. Ibid., p. 119.

46. Ibid., p. 273.

47. Vid. González Calvo, José Manuel. «Latinismos, cultismos». En Creatividad y expresividad en Fray Gerundio de Campazas. Cáceres: Universidad de Extremadura, 2017, pp. 113-159.

48. MARTínez. Op. cit., "Prólogo» [s. p.]. 
Y todavía al final de su carrera, en el último tomo de las Cartas eruditas (1760), insistiría Feijoo en censurar que el conocimiento del latín fuera indispensable en la práctica de la medicina: "Cosa irrisible y juntamente lastimosa. Porque ¿qué conexión tiene la lengua latina con las operaciones quirúrgicas?»; al revés, «yo estoy tan lejos de apreciar la latinidad en un cirujano, que antes la miro como circunstancia que justamente puede inducir a descartarle» (CE, V, 23, § VIII, 42) ${ }^{49}$. Así lo había defendido ya en 1742, en el caso de su amigo el cirujano francés Juan D'Elgart, ante el intento de impedir su contratación por el Ayuntamiento de Oviedo con el pretexto de no saber latín ${ }^{50}$. Pero lo que podía ser evidente para la razón natural aún hallaría contrario con el Dictamen sobre reforma de estudios médicos leído en 1768 ante la Academia Médico-Matritense por Andrés Piquer, quien redactaba sus tratados médicos en latín: "Los estudiantes de medicina han de saber latín decentemente [...]; es cosa extravagante que se fíe la salud de los hombres a quien no se puede fiar un párrafo de lengua latina ${ }^{51}$.

El prestigio facultativo del latín para ciertos ejercicios profesionales seguía siendo grande, como se verá enseguida a propósito de la polémica médica de Feijoo con el doctor Ros y su respuesta en la "Veritas vindicata» del tomo segundo del Teatro; o como trasluce el epígrafe al frente de la carta 16 del tercer tomo de las Cartas eruditas, la titulada "Sobre cierta lesión de la vista de un caballero", donde aclaraba que, "como la respuesta a la señora es ordenada a que la vean los médicos consultantes, no debe extrañar el lector los textos latinos y noticias físicas, anatómicas y matemáticas que hay en ella ${ }^{52}$. Pero la cita, que parecía indicar que la ciencia seguía hablado latín, ofrecía en cambio testimonio de que los latines ya estaban fuera del alcance del lector común al que aspiraba Feijoo, del vulgo (y "debajo del nombre de vulgo, comprehendo no pocas brillantes pelucas, no pocos venerables bonetes, no pocas reverendas capillas", como escribía en la carta precedente, CE, III, 15, 22) ${ }^{53}$.

La ciencia aprendía, pues, a abandonar el latín, convertido ya en un sociolecto más selectivo que comunicativo. Seguir pensando lo contrario "pende de falta de noticias; siendo cierto que de todas ciencias y artes hay mucho y muy excelente impreso en lengua francesa” (CE, V, 23, § IX, 47) ${ }^{54}$. El proceso sociolingüístico

49. FeIjoo. "Disuade a un amigo suyo el autor el estudio de la lengua griega...", pp. 391-392.

50. Ibid., pp. 392-393. Para una noticia ampliada, vid. Villa Río, María Palmira. Casal en Oviedo. Estudio documental de los médicos, cirujanos y boticarios de Oviedo en el siglo XVIII. Oviedo: Instituto de Estudios Asturianos, 1967, pp. 232 y ss.; 274-275. La cuestión, no obstante, iba más allá de lo lingüístico, pues la elección de "cirujano latino" por parte del Ayuntamiento tocaba en realidad a la posesión del título oficial del Protomedicato y la vigencia de su autorización. Feijoo se ofreció incluso a servir de traductor latino para su amigo, sin resultado.

51. Andrés Piquer apud LáZARO Carreter. Op. cit., p. 167.

52. FEIJOO. "Sobre cierta lesión de la vista de un caballero". En Cartas eruditas y curiosas [...], tomo tercero. Madrid: Herederos de Francisco del Hierro, 1750, p. 182.

53. FEIJOO. "Contra la pretendida multitud de hechiceros" (carta 15). Ibid., pp. 180-181.

54. FeIJOO. "Disuade a un amigo suyo el autor el estudio de la lengua griega...", p. 393. 
advertido por Feijoo se resumía en una vulgarización que podía encontrar, paradójicamente, excesos opuestos, pues los «latinos" tenían razones para notar una afectación análoga en el abuso de los galicismos por los modernos: "quos neotericos dicimus cultissimi latinorum ${ }^{55}$.

Pero quizá era inevitable que fuera así; los nuevos paradigmas señalaban las nuevas utilidades y prioridades. Incluso Campomanes, resignado, justificaba el gusto por el afrancesamiento lingüístico de Feijoo, signo de los tiempos, y se consolaba en perspectiva: "La lectura continua de las obras francesas le hizo interpolar [a Feijoo] algunos galicismos. Cicerón, con la lección de los originales griegos y el estudio que hizo en Rodas, no se libró de incurrir en belenismos ${ }^{56}$.

\section{LOS latines de FeijOO}

Será útil confrontar ahora la opinión de Feijoo sobre las culturas y lenguas clásicas con su praxis literaria. Dando por sentado que el latín formaba parte de la vida cotidiana de un eclesiástico del siglo XVIII, y suponiendo su protagonismo en la formación inicial y en los usos y costumbres de la vida regular de un benedictino, como disponían la regla de la orden y las constituciones de la Congregación de Valladolid, a la que pertenecía Feijoo, es clara su familiaridad con la lengua latina y sus obras principales tanto en literatura, historia y filosofía como en las teologías escolástica y expositiva, que formaban parte de la ratio studiorum de los centros eclesiásticos ${ }^{57}$. A su formación pertenecen cinco de los seis textos latinos de consideración que se conocen de Feijoo: la preceptiva hoja de grados (Salamanca, 1698), un volumen de tres manuscritos con las lecciones escolásticas de su

55. ISLA. Op. cit., p. 97.

56. [CAMPOMANES]. Op. cit., p. XII.

57. En el siglo XVIII, las lecciones cotidianas de latín eran obligatorias desde novicios. No obstante, en la Regla de San Benito de la congregación vallisoletana, edición bilingüe de 1751 de fray Diego Mecolaeta, se aclaraba: "La forma de la profesión es substancialmente la misma en todas las congregaciones benedictinas, aunque varíe en algunas palabras; y porque en la nuestra se escribe y lee en latín, que no entienden todos, especialmente los novicios (aunque no se puede dudar que a todos la explican sus maestros) me ha parecido que les obsequio si la pongo en romance, para que la entiendan sin necesitar de otro que se la interprete o explique" (Regla de nuestro padre san Benito [...]. Madrid: Antonio Pérez de Soto, 1751, p. 120).

Aun después de profesos, los monjes juniores debían asistir a lección diaria de gramática latina. Advertían las Constituciones de la Congregación de nuestro glorioso padre san Benito de España e Inglaterra. Madrid: Viuda de Melchor Álvarez, 1706: «En todo el discurso del año tres cuartos de hora antes de tocar a tercia, o a la hora que el prelado dispusiere, se tañerá a lección de Gramática, que ha de durar dichos tres cuartos de hora; a que asistirán todos los juniores para perficionarse en la latinidad, y les leerá la persona que el abad ordenare. El cual lector queremos que tenga autoridad para quitar el vino al que faltare a la lección o al que no diere bastante cuenta de lo que se leyere» (lib. II, cap. VII, 12, p. 174). Después, para entrar de colegial y ser pasante se prescribía: "Mandamos que el abad de la casa que hubiere de enviar colegial al colegio le examine primero en el Consejo así de sus costumbres como de la latinidad que sabe» (lib. III, cap. III, 2, p. 289). 
etapa de lector de Artes en San Salvador de Lérez (1704 a 1707) ${ }^{58}$, así como una carta-respuesta impresa en la que defiende su censura a Gonet $(1724)^{59}$.

Mención aparte merece la "Veritas vindicata", su texto latino más extenso, colofón al tomo segundo del Teatro crítico (1728) y respuesta al doctor Ignacio Ros, autor de una Medicina vindicata (1727) publicada contra Feijoo en el curso de las polémicas por la Medicina escéptica de Martínez. Feijoo no alcanza la razón por la que Ros escribe su diatriba en latín - Quae vero necessitas scribendi latine?" (TC, II, [18], § I, 5)- ${ }^{60}$ y lo toma por una provocación desafiante. Recoge el envite respondiendo con suficiencia del mismo modo y publicando la traducción en el tomo siguiente:

No puedo comprehender qué motivo obligó a este autor a escribir en latín. Acaso contemplándome extranjero en este idioma, o el idioma extranjero para mí, quiso obligarme a responder en él, para que embarazado en la dificultad del estilo, o me diese por vencido a la impugnación, o en vez de explicarme, me implicase en la respuesta. Es cierto que con no poca repugnancia me he reducido a responder en el idioma latino; porque mi distancia del lugar destinado a la impresión me imposibilita corregir las muchas erratas que preveo ha de haber por la impericia del impresor; y no faltará algún caviloso contrario mío que maliciosamente me las impute, transfiriendo a mi persona el defecto de la latinidad o la ignorancia del que imprime la obra (TC, III, [14], § I, 6) ${ }^{61}$.

58. FeIJOO. Assertiones Theologicae juxta mentem magni parentis nostri Anselmo et Angelici Praeceptoris (Salamanca: s. i., 1698). Hoja de grados que recoge, impresas, las seis conclusiones de su tesis de Teología, leída en el colegio de San Vicente de Salamanca el 9 de marzo de 1698. Y los manuscritos Philosophici cursus. Disputationes in Philosophia rationale seu Aristotelis dialectica complectens, 1704, 125 fols.; Comentaria in Aristotelis Metaphisicam, 1706, 248 fols.; Comentaria in universalem Aristotelis Philosophiam naturalem, 1707, 111 fols. (Santiago de Compostela, Biblioteca Universitaria).

Estos dos manuscritos recogen las enseñanzas impartidas por Feijoo entre 1704 y 1707, trasladadas por el pasante y, suponemos, alumno suyo Matías de la Vega. Los textos permiten descubrir a Feijoo como maestro de pasantes en Lérez ya en 1704, y no como pasante. Esas cerca de mil páginas de un "limpio latín escolar» son estudiados por Ramón López VÁzQuEz. O Padre Feixoo, escolástico. Santiago de Compostela: Centro de Investigacións Lingüísticas e Literarias Ramón Piñeiro, 1995 (la cita, p. 32).

59. Sapientísimos Patres Magistros Fr. Joseph Barrio et Fr. Dominicum Ribera, Sacrae Theologiae Lectores in Studio Generali Regii Conventos Sanctae Crucis Segovienses Ordinis Praedicatorum, reverenter atque amanter resalutat (1724) (Salamanca. Biblioteca Universitaria).

60. FEIJOO. "Veritas vindicata adversus medicinam vindicatam" [discurso 18]. En Teatro crítico universal [...], tomo segundo. Madrid: Francisco del Hierro, 1728, p. 359.

61. Feijoo desliza una justificación pragmática y sociológica para no publicar en latín: no por su dificultad particular sino por su ignorancia generalizada. Para preservar, pues, la comunicación más competente de sus escritos. Y le devuelve doblado el envite a Ros: "Este miedo de los yerros de imprenta (por la ignorancia de latinidad que hay en nuestros impresores) se acrecienta en mí, en consideración de los muchos que he observado en el escrito del doctor Ros. Si este autor, no obstante la cuidadosa vigilancia que es de creer aplicaría a la corrección de su obra, no pudo evitar que cayesen en ella muchísimos solecismos y barbarismos, ¿cómo podré yo, estando ausente, evitar igual o mayor desgracia en la mía?» ("La verdad vindicada contra la medicina vindicada. Respuesta apologética 
El cotejo de teoría y práctica del cultivo latino de Feijoo debe comenzar por sus fuentes bibliográficas, que estudia Agustín Hevia Ballina ${ }^{62}$. Del análisis de su biblioteca clásica resulta el amplio conocimiento que tenía de la cultura antigua, en atención a sus citas de los principales autores y a su solvente expresión en latín. Porque, aparte de su formación en el latín bíblico y escolástico y su instrucción en una amplia base humanística, siguiendo los métodos de las Repetitiones, debemos añadir su conocimiento anterior, probablemente de la casa paterna, de algunos poetas clásicos, sobre todo de Virgilio, cuyos versos cuenta que recitaba de memoria su padre (TC, IV, $14, \S 23,85)^{63}$.

El análisis de la librería latina de Feijoo no lleva más comentario que las ausencias puntuales de los principales autores, a alguno de los cuales citaba, no obstante, de memoria, como indica su hábito de parafrasear sin localizar con precisión la fuente; por ejemplo, a Cicerón (TC, VI, 2, § III, 33; TC, VII, 10, § I, 3; TC, VIII, 12, § XIV, 91; CE, I, 38, 5; CE, III, 22, 18; CE, V, 2, 59); o como demostró al improvisar la recitación de versos latinos remedando el exorcismo ante una falsa poseída: "Empecé, pues, mis singulares conjuros, que consistían [...] en versos de Virgilio, Ovidio, Claudiano y otros poetas» (TC, VIII, 6, § VII, 30) ${ }^{64}$. Aun así, todo estudio bibliográfico y de fuentes en Feijoo debe partir del hecho de que los catálogos de su biblioteca personal o los del monasterio y colegio de San Vicente poco concluyen de sus lecturas reales, pues, corresponsales, correligionarios y amigos aparte, disponía también de la modesta librería universitaria de Oviedo, así como de la nutrida biblioteca del colegio jesuita de San Matías, muy utilizada por los miembros de la comunidad universitaria y que era la más copiosa de la ciudad, antes que las de Santo Domingo o San Francisco ${ }^{65}$.

En cuanto a las obras de su particular biblioteca helenística, casi todas deben de haber sido traducciones latinas y alguna francesa. Pues, pese a los «escarceos etimológicos» que abundan en su obra, Hevia Ballina constata que se extraen del

traducida de latín en castellano y añadida por el autor». En Teatro crítico universal [...], tomo tercero. Madrid: Francisco del Hierro, 1729, p. 337).

62. Hevia Baldina, Agustín. "La biblioteca clásica del Padre Feijoo». En VV. AA. II Simposio sobre el Padre Feijoo y su siglo (I). Oviedo: Cátedra Feijoo, 1981, pp. 375-392.

63. Feijoo. "Glorias de España. Segunda parte» (discurso 14). En Teatro crítico universal [...], tomo cuarto. Madrid: Viuda de Francisco del Hierro, 1730, p. 412.

64. FeIjoo. "Demoníacos" (discurso 6). En Teatro crítico universal [...], tomo octavo. Madrid: Herederos de Francisco del Hierro, 1739, p. 94.

65. Hevia Baldina, Agustín. «Un nuevo acercamiento al padre Feijoo: el catálogo de la librería del monasterio de San Vicente de Oviedo». Studium Ovetense, 1980, vIII, pp. 311-344. Para una noticia histórica, vid. RoDríguez Álvarez, Ramón. La Biblioteca de la Universidad de Oviedo (1765-1934). Oviedo: Universidad de Oviedo, 1993, pp. 21-22; 29 y ss. Otro depósito principal de noticias bibliográficas para Feijoo era su colaborador Martín Sarmiento. Para un estudio de su biblioteca, a la que más adelante habrá ocasión de referirse, véase la tesis doctoral de Rocío AMENEIROS RODRíGUEz La biblioteca de Martín Sarmiento: recepción de la Ilustración en España (2015). En línea, Repositorio da Universidade da Coruña, https://ruc.udc.es/dspace/handle/2183/15946 [17/04/2020]. 
Lexicon Graeco Latinum de Scapula, y que Feijoo era, en efecto, ignorante de la gramática griega. Maneja, pues, por vía de traducción, a Platón, Aristóteles (de cuyas versiones latinas opina: TC IV, 7, § XVII, 58) ${ }^{66}$, Dioscórides, Hipócrates y Galeno, a quienes elogia por prudentes; Luciano de Samosata, en quien ve un satírico conjurado a su misma lucha contra errores comunes; los Caracteres de Teofrastro, las obras de Homero y la Historia de Polibio. O Plutarco - «el gran Plutarco» (TC, I, 16, § XIV, 98)-, uno de sus autores, no solo antiguos, más admirados, cuyas Vidas paralelas imita en sus propios paralelos históricos.

Cuestión afín es el aristotelismo de Feijoo ${ }^{67}$. En cuanto a su noticia directa de Aristóteles, el teólogo José Ignacio Saranyana, analizando el tomismo de Feijoo desde los estudios de Arturo Ardao, alcanza la equivocada conclusión de que «el conocimiento que Feijoo tenía de Aristóteles era escaso, limitado a las referencias que la Escolástica había recogido del Corpus del estagirita ${ }^{68}$. Lo dice del desprecio que Feijoo hace de las nociones naturales de Aristóteles, producto, según él, de su desconocimiento de la temprana Física aristotélica. Una tesis que ignora las fundadas averiguaciones de Hevia Ballina, cuando anota que Feijoo conoció a Aristóteles a través de la Escolástica y de las exposiciones del cardenal Sáenz de Aguirre, así como que "sintió especial curiosidad frente a algunos libros del estagirita, especialmente los de orientación hacia la física o las ciencias de la naturaleza " ${ }^{69}$.

A partir de los análisis bibliográficos de Hevia Ballina, José Filgueira Valverde quiso aquilatar la posición de Feijoo ante la Antigüedad clásica y sus semejanzas con su colaborador Martín Sarmiento. Por encima de sus coincidencias, destaca el "radical anticlasicismo» de Feijoo ${ }^{70}$, y cuantifica, con discutible criterio, sus citas de autores clásicos en solo la sexta parte de las autoridades a lo largo de su obra ${ }^{71}$. Si bien tampoco dice otra cosa de Sarmiento, quien en sus ideas pedagógicas

66. Feijoo. "Mérito y fortuna de Aristóteles...", p. 159.

67. Aparte del discurso anterior y varios lugares más, volverá a referirse al sistema de Aristóteles desde el desengaño de su filosofía natural en la carta «Sobre los sistemas filosóficos» (CE, II, 23). Para un resumen, vid. ARDAO, Arturo. La filosofía polémica de Feijoo. Buenos Aires: Losada, 1962, pp. 56-60.

68. Saranyana, José Ignacio. "Sobre el tomismo de Fr. Benito Jerónimo Feijoo". Scripta Theologica: Revista de la Facultad de Teología de la Universidad de Navarra, 1984, 16:1-2, p. 463.

69. Hevia Ballina. "La biblioteca clásica...”, pp. 380-381.

70. Filgueira Valverde, José. "Feijoo y Sarmiento ante la Antigüedad clásica». Cuadernos de la Fundación Pastor, 1983, 1, p. 15.

71. Conclusión que puede desmentirse con el estudio de fuentes de Rodrigo OlaY Valdés "Reconstrucción del canon poético en el ensayo de Feijoo". Cuadernos de Estudios del Siglo XVIII, 2013, 23, pp. 151-194. Con minuciosidad y racionalización de la estadística desmiente afirmaciones como las de Filgueira. Feijoo no podía citar a los clásicos por igual en las ciencias humanas o especulativas que en las ciencias útiles o los asuntos contemporáneos. Pero basta una cata literaria para reajustar la escala. Véase el epígrafe dedicado a los poetas clásicos, donde demuestra que «a diferencia de otras poéticas de su momento, pero al igual que Luzán, Feijoo cita mucho más a menudo a los poetas clásicos, sobremanera a los latinos, que a los poetas españoles generalmente más y mejor conocidos en el siglo XVIII" (p. 156). 
señalaba que los maestros debían formarse en las lenguas muertas solo para saber mejor lo que debían enseñar en la lengua viva castellana ${ }^{72}$. El mundo clásico estaría asimismo infravalorado en los repertorios bibliográficos del monje de San Martín de Madrid, y en su desiderata del buen gusto literario, el Catálogo de libros curiosos y selectos para una librería de un particular, Filgueira Valverde observa la sección de "Autores gentiles griegos y latinos" pobremente representada ${ }^{73}$.

Al igual que Feijoo, para Sarmiento, "los romanos han sido unos monos de los griegos en todo, en la lengua, en las leyes y ciencias" ${ }^{74}$. Sin embargo, el pragmatismo de Feijoo se atempera en Sarmiento, que no sacrificaba su curiosidad al economicismo funcionalista de una paideia ilustrada sin lenguas muertas. Filgueira Valverde utiliza el Sistema de adornos diseñado por Sarmiento (1743-1747) para el nuevo Real Palacio de Madrid, una prolija alegoría escultural sobrepuesta a la severidad neoclásica del edificio, como índice de los resabios antimodernos del monje, «un manifiesto romántico frente a la asepsia internacionalista de Sacchetti y de Olivieri» ${ }^{75}$. Como ha observado en su estudio de la sociedad literaria de estos dos sabios benedictinos Joaquín Álvarez Barrientos -editor a su vez del Sistema de adornos $-^{76}$, Sarmiento era un hombre más remiso al progresismo de tabla rasa, amante de lo excepcional o marginal, coleccionista de erudiciones, sensible a las lenguas vernáculas y la curiosidad etimológica ${ }^{77}$.

Por fin, en el estilo de Feijoo podríamos recuperar sus deudas reales con la Antigüedad. La naturalidad es el ideal que para él debe presidir la expresión literaria - Sin la naturalidad no hay estilo, no solo excelente, pero ni aun medianamente

72. Aguilar Piñal. Op. cit., pp. 228-229, lo identifica en el seno de una gran lucha castellanista frente al latín por la reforma universitaria. Aparte de Feijoo y Sarmiento, no deja de señalar en ella a Mayans, Forner o Capmany. A finales de siglo, Jovellanos seguiría en el mismo afán reformista, pero denostando ahora, al revés de lo que sucedía en la época de Feijoo, la generalización del latín en las aulas.

73. Las tesis del sabio pontevedrés se ven nuevamente puntualizadas, ahora bajo la lente biblioteconómica, con la tesis doctoral de Ameneiros Rodríguez: Sarmiento, lejos de minusvalorar a los clásicos, y contra el uso al elaborar catálogos bibliográficos, que era jerarquizar las secciones iniciándolas por los autores bíblicos, comienza los epígrafes temáticos de sus repertorios por los clásicos. Destaca la autora que Sarmiento era asesor para el griego de Campomanes y parte como él del círculo humanista madrileño de la Biblioteca Real. Op. cit., pp. 228-229, 249.

74. Martín Sarmiento apud Rodríguez EnNEs. Op. cit., p. 9.

75. Filgueira Valverde. Op. cit., p. 32.

76. Sarmiento, Martín. Sistema de adornos del Palacio Real de Madrid. Ed. Joaquín Álvarez Barrientos y Concha Herrero Carretero. Madrid: Sociedad Estatal España Nuevo Milenio, 2002.

77. Vid. Álvarez BarRIENTOS, Joaquín. «Para la historia de una amistad: Feijoo (1676-1764) y Sarmiento (1695-1772)». En URZaINQUI, Inmaculada y Olay Valdés, Rodrigo (coords.). Con la razón y la experiencia. Feijoo 250 años después. Oviedo: Instituto Feijoo de Estudios del Siglo XvII/Universidad de Oviedo/Trea, 2016, pp. 489-508; «Martín Sarmiento (1695-1772), o la escritura como gabinete de curiosidades». En LORENZO ÁlvareZ, Elena de (coord.). Ser autor en la España del siglo XVIII. Gijón: Trea, 2017, pp. 83-112. 
bueno. ¿Qué digo ni aun medianamente bueno? Ni aun tolerable» (CE, II, VI, 2)_ ${ }^{78}$ : la elocuencia dependía del ingenio natural y no de la imitación académica de modelos, lo que se traducía en una poética que pudo interpretarse como anticlasicista y antiluzaniana. Sobre esa explicación del gusto feijoniano se erigió su retrato prerromántico, desde que Menéndez Pelayo quiso redimir a Feijoo de su francesismo leyéndolo en oposición a Luzán y los preceptistas "galoclásicos»" Operaba así la maniobra de convertir al protoilustrado en prerromántico, con «sus libérrimas doctrinas de estética general", sus opiniones, "paradójicas a veces, revolucionarias siempre», sobre estética, que podían llevarlo «a sentar uno de los dogmas capitales de la escuela romántica». Así, en algo tan supuestamente español como «la reivindicación constante, sistemática y apasionada de los derechos y libertades del genio", Feijoo aparecía como adelantado del casticismo romántico ${ }^{80}$.

Siguiendo la deducción, los estudios estilísticos posteriores tendieron a minimizar, no obstante, su carácter libérrimo. Así Rafael Lapesa al destacar que la sedicente naturalidad del estilo de Feijoo no deja de ceñirse a estructuras artificiosas. Pero, lejos de su previsible lectura clasicista, Lapesa las ve extraídas del molde barroco. Su escritura armoniosa, eurítmica, de aparente pauta ciceroniana, abundante en cláusulas y períodos, simetrías y paralelismos, entroncaría antes con una escolástica aliviada de rigidez silogística o con Quevedo, Saavedra Fajardo o Gracián, en el uso de las imágenes. Comoquiera, y al igual que hemos visto en Filgueira Valverde y se hará norma, Lapesa confirmaba la observación anticlasicista y romanticista de Menéndez Pelayo: «Feijoo continúa de una parte el gusto barroco por la bizarría expresiva, pero por otro anuncia la exaltación sentimental del prerromanticismo»" ${ }^{81}$. Y aunque más adelante este mismo diagnóstico también habría de atenuarse, por ejemplo, con los estudios de Russell P. Sebold o José Checa Beltrán, ha pervivido el dictamen de un autor alejado del clasicismo, por más que con sus mismos argumentos se lo pudiera considerar en la clave horaciana de la oposición ars/natura; y por más que el rechazo de la imitación no dejara de estar en la pluma del autor de la Epistola ad Pisones: «Siguiendo a Horacio, de quien es aquella invectiva: ¡Oh imitatoris servum pecus! [iOh, imitadores, rebaño de siervos!]» (CE, II, 6, 8) ${ }^{82}$.

78. FeIJOO. "La elocuencia es naturaleza y no arte» (carta 6). En Cartas eruditas y curiosas [...], tomo segundo. Madrid: Herederos de Francisco del Hierro, 1745, p. 45.

79. MenÉndeZ Pelayo. Op. cit., p. 284.

80. Ibid., pp. 207-215. Feijoo ya se había expresado sobre el irracionalismo del gusto estético y poético en el discurso «El no sé qué» (TC, VI, 12), que Menéndez Pelayo calificaría, en el mismo lugar, de "manifiesto romántico".

81. LAPESA, Rafael. "Sobre el estilo de Feijoo". En VV. AA. Mélanges à la mémoire de Jean Sarrailh, t. II. Paris: Centre de Recherches de l'Institut d'Études Hispaniques, 1966, p. 28.

82. FeIJOO. "La elocuencia es naturaleza y no arte», p. 47. Para un breve recorrido crítico, vid. su edición crítica en Cartas eruditas y curiosas [...], tomo II. Ed. Inmaculada Urzainqui, Eduardo San José Vázquez y Rodrigo Olay Valdés. Oviedo: Instituto Feijoo de Estudios del Siglo XviII/Ayto. de Oviedo/ Krk Ediciones, 2018, n. 1, pp. 90-91. Para la afirmación feijoniana del principio horaciano Ut pictura 


\section{4. ¿CASTICISMO VERSUS CLASICISMO?}

Al recoger los sentidos dispersos de lo que Feijoo escribió sobre la cuestión y de todo lo que sobre ello se ha considerado, se perfilan dos posturas críticas coincidentes en las observaciones pero dispares en su selección e interpretación. Divergencia derivada de que críticos e historiadores han querido suponer las intenciones de Feijoo, además de examinar el asunto a través de un sesgo único nacionalista.

El problema territorial y la discusión por los meridianos culturales de España tras la guerra de Sucesión han guiado, así, la lectura crítica de las tesis de Feijoo sobre el cultivo clasicista. Pero, en rigor, nuestro autor se manifestó por: 1) la admiración condicionada y no gregaria a los clásicos; 2) la prevalencia utilitaria del latín ante el griego; y 3) la limitación de los fueros actuales del latín. Una única proposición (funcionalismo en la adopción de los modelos culturales), expuesta en tres enunciados.

Sin embargo, dependiendo de a cuál de los tres se decidiera dar fuerza, la misma opinión impresa fue tomada como casticismo romántico por Menéndez Pelayo (el anticlasicismo feijoniano, como antineoclasicismo, o sea, antifrancesismo). O bien, como muestra de un funcionalismo a ultranza, o sea, una extensión del uniformismo castellanista en contra de la variedad vernácula y del vencido foralismo. Ambas posturas críticas coinciden, pues, tanto en el anticlasicismo de Feijoo como en asignar a sus opiniones, como blasón o como baldón, una tácita intención españolista o castellanista.

Las reacciones a las propuestas de Feijoo entre los contemporáneos han quedado esbozadas. Desde el rechazo de humanistas ilustrados como Mayans y Lanz de Casafonda o las reservas de Campomanes, hasta la adhesión o cuando menos la coincidencia del círculo extenso del benedictino, Sarmiento, Isla o Codorniu. Estos eran correligionarios de Feijoo o jesuitas próximos desde tiempo atrás al primer programa borbónico de reformas y en distinto grado a los favorecedores iniciales de Feijoo en la corte (Rávago, Goyeneche, Patiño, Carvajal, etc.).

Por su parte, Mayans, como Manuel Martí, austracistas reconvertidos y representantes de lo que Antonio Mestre caracteriza como un "rescoldo foral evidente entre los partidarios valencianos de las nuevas ideas" ${ }^{83}$, escribieron el grueso de su obra en latín, sintiéndose en alguna medida depositarios de la escuela humanista valenciana, encabezada por Luis Vives. Mayans se opuso con disgusto y con burla a las observaciones de Feijoo, que tomó por el signo de los tiempos en lo que a la cultura se refería: extensión sin profundidad.

poesis, vid. MenÉndez Pelayo. Op. cit., p. 211. Para la influencia de la poética horaciana en Feijoo, vid. Olay Valdés. Op. cit., pp. 169-171. Cfr. BoBEs, Carmen y otros. Historia de la teoría literaria. I. La Antigüedad grecolatina. Madrid: Gredos, 1995, pp. 189-190.

83. Mestre. Op. cit., p. 305. 
Las implicaciones políticas y culturales de la controversia han sido objeto de la crítica posterior; connotaciones que, o bien pasaban desapercibidas para los protagonistas, o bien, lo más probable, eran tan evidentes para todos que ninguno las aludía en el curso de la discusión por el cultivo de las lenguas clásicas. Ese ha sido trabajo de los historiadores, acometido en ocasiones de forma sesgada.

Por un lado, comprobamos que, en la línea de Menéndez Pelayo, de larga hegemonía en la historiografía literaria, Filgueira Valverde, por ejemplo, continuará identificando a Feijoo «en lo que es forzoso llamar, aun fuera de su área temporal, "la mentalidad romántica" , y lo erige de hecho en paradigma de "un temprano Romanticismo muy adecuado a la mentalidad española", frente al cual el clasicismo solo habría sido una reacción ${ }^{84}$. Siguiendo el discurso que hacía del siglo XVIII y de la Ilustración una interrupción en la cultura hispánica, una importación extraña entre el Barroco y el Romanticismo, el pretendido anticlasicismo de Feijoo era una ocasión para reasimilarlo a la ortodoxia de la historia de la literatura española.

Por el contrario, avanzado el siglo xx el énfasis crítico se puso en hacer de Feijoo un agente cultural del absolutismo borbónico. Como tal, Mestre lo retrata sobre su fondo político como un autor formado, sí, en el antiescolasticismo y la apertura a la cultura profana y al humanismo por vía de la nueva historiografía crítica de los benedictinos maurinos; pero, al mismo tiempo, como un crítico a medio camino, reacio a llevar a su consecuencia ese género de influencias. Y ello, por subordinar su desengaño crítico al nacionalismo español:

Los benedictinos de la Congregación de Valladolid, aun los relacionados con San Mauro, siempre mantuvieron un acusado espíritu nacionalista, tanto en la defensa de la pronta implantación de la orden de San Benito en España o de los santos benedictinos, como respecto a las grandes tradiciones nacionales sobre los orígenes apostólicos del cristianismo en España.

Puesto ese nacionalismo al servicio de la nueva política cultural borbónica, de la que "Feijoo no se desvío un ápice», concluye Mestre que "nuestro benedictino fue más sensible a la oportunidad política que a las exigencias de la crítica histórica ${ }^{85}$.

En un orden de conclusiones coincidente, Xosé Antonio López Silva ha entendido la posición de Feijoo ante el cultivo las lenguas clásicas como un elemento de

84. Filgueira Valverde. Op. cit., pp. 11-12.

85. Mestre. Op. cit., pp. 300, 307. Seguirá considerando a Feijoo no un humanista sino un ensayista que "se inclinaba más por el escepticismo mecanicista que por el humanismo", encarnado por Mayans ("Científicos y humanistas en la Ilustración española». En AlBEROLA-Romá, Armando y otros. Jorge Juan Santacilia en la España de la Ilustración. Sant Vicent del Raspeig: Universitat d'Alacant, 2015, pp. 30-31). Mestre identifica una dialéctica crítica-apología que recorre el siglo, en la que le rebaja el nervio crítico a Feijoo por su apología española. A su vez, no obstante, también aprecia la reivindicación humanista de Mayans y otros como apologética, frente a la acusación europea de barbarie. Vid. Apología y crítica de España en el siglo XVIII. Madrid: Marcial Pons, 2003, p. 24. 
la receta centralista y uniformista del regalismo borbónico (aun cuando la relación de Feijoo con el absolutismo y la razón de Estado merecería otro desarrollo). En efecto, una buena piedra de toque del asunto es la mayor polémica clasicista que mantuvo Feijoo, su preferencia de la poesía épica de Lucano frente a la de Virgilio, por su fidelidad a la historia frente a la ficcionalización del mantuano, controversia que es estudiada en detalle por López Silva, desde Mestre, Álvarez Barrientos y otros $^{86}$. Este juicio poético, expresado en el tomo IV del Teatro ("Glorias de España, segunda parte», números 39 a 43, luego ampliados en el Suplemento), tiene un innegable centro de gravedad patriótico, que es el que agrupa los asuntos de ese discurso doble. Y, así, lo habitual ha sido suponerle a Feijoo un celo patriótico capaz de cegarle la razón y el buen gusto; pues preterir al Príncipe de los Poetas ante Lucano, poeta cordobés, no parece tener otro fundamento. Menéndez Pelayo juzgaba a Feijoo "guiándose más bien por disculpable amor patrio que por legítimo sentimiento artístico", pues "en el fondo sostenía la causa de Lucano por el mero hecho de haber sido Lucano español ${ }^{87}$. Pero apenas se ha considerado que, lejos de mostrar cualquier "romanofobia» con esta opinión, Feijoo sería coherente con el realismo de la preceptiva clásica. Desde él se refiere a Lucano en el Suplemento (1740) del tomo segundo del Teatro como «el único poeta que no mintió, o mintió poco» (TC, II, 2, § VIII, $47\{5\})^{88}$.

La misma acusación implícita de romanofobia españolista expresa López Silva al señalar el "curioso ejercicio de paradojismo retórico" de Feijoo cuando ataca a la Roma invasora de Hispania ${ }^{89}$. Observación muy cierta, por lo demás. Pero, no obstante, deja de merecer un comentario equivalente el hecho de que, como ya hiciera Nicolás Antonio en su Bibliotheca Hispana, Feijoo está emplazando la historia literaria nacional en clave hispanolatina - "nuestros mayores", había llamado a los antiguos-90, y así será continuada por Sarmiento, los hermanos Mohedano, José Rodríguez de Castro o Menéndez Pelayo, en su Bibliografía bispano-latina clásica (1902).

Con la misma lógica, habría que anotar entonces que Feijoo excluye como un paréntesis en su recorrido al-Ándalus, tal como subraya Robert Ricard: «Feijoo

86. López Silva, Xosé Antonio. «Feijoo contra los virgilianistas. La polémica sobre Lucano en el siglo XVIII». En GARCía JuRAdo, Francisco y GONZÁlEZ GonZÁlez, Marta (eds.). La historia de la literatura grecolatina en España: de la Ilustración al Liberalismo (1778-1850). Málaga: Analecta Malacitana (Anejo XC), 2013, pp. 375-394.

87. MenÉndez Pelayo. Op. cit., pp. 209-210.

88. Feijoo escribe esto después, en el Suplemento, y no en el tomo de 1728: responde así a la polémica generada, sobre todo, con Mayans. En las adiciones del Suplemento al tomo IV seguirá defendiéndose de españolismo: "Confieso que sería insigne temeridad sostener por mi capricho solo la igualdad, mucho más la preferencia de Lucano a Virgilio. Mas entretanto que hallo votos de la más alta clase y desnudos de toda parcialidad a favor de nuestro español, no es justo abandonar su partido» (Suplemento a TC, IV, 13, 39).

89. López Silva. Op. cit., p. 378.

90. FeIjoO. "Resurrección de las artes...", p. 281. 
n'était pas un isolé, et il pouvait se réclamer d'une tradition déjà longue, celle qui établissait comme lui une continuité sans rupture entre l'Espagne romaine, l'Espagne wisigothique, l'Espagne du roi Pelayo et l'Espagne moderne»; pero había en el relato una falsa continuidad, pues, "ce que Feijoo bannit sans le dire de la tradition espagnole, contrairement à certaines vues de notre époque, c'est la période musulmane „"1.

De aquí se desprende que Feijoo no elabora un relato español anticlásico, sino un relato hispánico cristiano, como era difícil que fuera de otra forma en su caso. Una historia de la literatura y la cultura española que no ignora la existencia de una España prerromana, pero interpretada para la posteridad en la clave de la Hispania latina, con la interrupción de al-Ándalus o "la pérdida de España» (TC, IV, 13, § XV, 53).

A excepción, pues, de la cuestión religiosa, el esencialismo casticista o de cualquier otra índole está lejos del autor del discurso "Paralelo de las lenguas castellana y francesa" (1726) o de la carta "Defiende el autor el uso que hace de algunas voces o peregrinas, o nuevas en el idioma castellano» (1742). El expurgo de las antigüedades onerosas que solo en cierta medida propone Feijoo no debe verse, pues, como parte de un programa de exaltación castellanista, cuando la propia lengua española no tenía, para él, rango ni privilegio frente al francés o cuanta lengua, así fuese de herejes como el inglés, se mostrara más apta para la crítica útil. En esta clave deben examinarse antes las intenciones de Feijoo, de acuerdo con sus palabras, y restituirse en el eje más expresivo que es la polémica entre antiguos y modernos.

En ella, el benedictino tuvo clara su filiación entre estos. Pero no como un radical anticlásico ni como agente de una modernidad de tabla rasa. Así se ve en los muchos ejemplos que regala el discurso "Resurrección de las artes y apología de los antiguos", tan poco citado en los estudios de esta cuestión. Un texto que habla también del concepto de progreso en Feijoo y de sus cautelas hacia el optimismo de la modernidad, que pocas creaciones ha aportado desde Grecia y Roma: "No solo [...] el ingenio de los antiguos en nada fue inferior al de los modernos, mas también [...] los modernos injustamente se jactan de inventores en muchas cosas de que realmente lo fueron los antiguos». Toda modernidad era renacimiento, con una sola salvedad:

Una ventaja no puede negarse a los modernos para adelantar más que los antiguos en todo género de ciencias; pero debida no a la habilidad sino a la fortuna. Esta consiste en la mayor oportunidad que hay ahora de comunicarse mutuamente los hombres, aun a regiones distantes, todos los progresos que van haciendo en cualesquiera facultades (TC, IV, 12, § III, 5) ${ }^{92}$.

91. RICARD. Op. cit., pp. 295, 298.

92. FEIjOO. "Resurrección de las artes...", p. 283. 
Comunicación que no dependía solo de los mejores caminos, sino del gran aporte de la primera modernidad, la imprenta. Examinando cada campo del saber, Feijoo expone en este discurso que la modernidad ilustrada solo es capaz de enrostrarle a la Antigüedad la ventaja de la comunicación. Modernidad significaba, en suma, comunicación; y para ella las lenguas debían ser su medio y no el fin.

\section{CONCLUSIÓN}

Tanto por la vía eminente de los antiguos como por la del Renacimiento español $^{93}$, en Feijoo comprendemos a un amante de los clásicos desengañado no de su ejemplo sino de su utilidad presente y de la posibilidad de su cultivo. Al excluir de su afición por la Antigüedad el aprendizaje de la lengua griega y querer restringir la importancia social y científica del latín, se justifica por las limitaciones de la España contemporánea. Esto es, por falta de maestro competente, en el primer caso - la misma razón que Mayans aducía para no saber bien el griego-; y por ley de uso, en el latín. Solo entonces hace de la necesidad virtud, relegando el gusto de leer de primera mano a los griegos para invertir el tiempo en aprendizajes más útiles.

Descubrimos así las precariedades culturales de la época y sus soluciones de urgencia, como aplicar a las curiosidades eruditas un uniformismo de sentido práctico: retrato de todas formas caricaturesco, en que Feijoo figura como la muela cultural del rodillo borbónico. En vez de esto, y mirando la polémica bajo la lente más ajustada del posibilismo, Luis Gil censura la "comodidad de la solución» de Feijoo para el porvenir del griego en las ciencias humanas y la compara con el desdén hacia las ciencias útiles del que inventen ellos del catedrático de griego: un curioso quiasmo, paradoja de los tiempos, entre el pragmatismo feijoniano y el idealismo unamuniano. Para Luis Gil, la extremosidad del carácter hispano ha llevado muchas veces a resolver los problemas eliminándolos ${ }^{94}$. Si bien no reconocemos en esto a Feijoo, no podemos tampoco obviar lo que dejó escrito. Acaso sí leerlo al completo, y realzar también el contexto en que se escribieron las dos cartas señaladas, esto es, 1760, al poco de la subida al trono español de Carlos III, a quien dedica el tomo recién llegado como rey de Nápoles y las Dos Sicilias.

Si congraciarse con el proyecto del nuevo monarca hubiera estado en la mente de Feijoo, ¿no serían esas propuestas un gesto imprudente hacia el rey arqueólogo de Herculano y Pompeya? Mucho más si, como señala López Silva, el pleito ente virgilianistas y lucanistas se había leído como una ramificación de

93. Vid. Olay Valdés. Op. cit., pp. 153; 175-178; 188-189. Desde Alberto Blecua, Inmaculada Urzainqui y otros, considera a Feijoo, como Mayans, patrocinador de una vuelta a los modelos literarios del siglo XVI español.

94. Vid. Gil. Campomanes, p. 21. 
la polémica entre la literatura española y la italiana ${ }^{95}$. Nótese que el monarca le había obsequiado con los primeros tomos de la fastuosa edición de Le antichità di Ercolano, emprendida en Nápoles en 1757 (si bien el gusto pompeyano, como vía de entrada para el neoclásico, tardaría aún en prender en España y en Europa, por mediación de Winckelmann) ${ }^{96}$. Nada más lejos, pues, que dirigir sus dos últimos impresos por otro razonamiento que no fuera el de la honesta utilidad.

Apenas se ha estudiado así, pero convendría verificar si los estudios clásicos eran más afectos a los austracistas o reconvertidos como Martí o Mayans que a otros ilustrados borbónicos llamados por el neoclasicismo. De modo que, sacándola de la secundaria cuestión nacional, la explicación sobre el clasicismo de Feijoo quizá fuera más exacta en la polémica entre antiguos y modernos.

En su conocido ensayo Ideología de los estudios clásicos, Luciano Cánfora se atrevió a asignar connotaciones políticas estables al clasicismo, algo que, con toda cautela, quizá pueda guiarnos por lo que Feijoo pudo tener o no de clasicista. La fascinación profunda hacia estos estudios radicaría en un solo hecho: están reservados a unos pocos. Enseguida, Cánfora identifica dos posturas ideológicas ante los estudios clásicos: «la cultura "antidemocrática" les otorgará por lo general un papel relevante, mientras que, por el contrario, serán puestos en discusión en aquellos lugares en los que se lleven a cabo experimentos de "cultura de masas" ${ }^{97}$. El elitismo inherente al clasicismo atravesaría por un espejismo progresista, la apropiación ingenua de la democracia de las repúblicas antiguas por el jacobinismo. Ese regreso áureo a las «democracias antiguas» -confundidas con la soberanía popular, pero oligárquicas y esclavistas- es efímero y deriva, como la historia antigua, en un Imperio. Tal sería, pues, la norma del clasicismo: una fase republicana antes de alcanzar su esencia imperial, el cesarismo.

Quizá por esto, y no está diciendo otra cosa a sus lectores, Feijoo rechaza el cultivo del griego y restringe el latín porque los interpretaba en su contexto como instrumentos selectivos. Y, con todo ello, Feijoo quizá no haya sido un clasicista evidente o inmediato, pero sí lo fue en su carácter moderno, pues, como explica Domingo Ynduráin, todo clasicismo es la emulación de una idea construida, no la repetición de un pasado del que necesita alejarse: "Es la ruptura, no la continuación del pasado lo que caracteriza la nueva actitud intelectual». Y acotar el

95. López Silva. Op. cit., p. 391.

96. Vid. el ejemplar trabajo de María del Carmen Alonso RodríGuez, "La Antigüedad al servicio del rey. La difusión del gusto pompeyano en España en el siglo XVIII". Cuadernos Dieciochistas, 2018, 19, pp. 105-137. En la biblioteca particular de Feijoo se registran al menos los tres primeros tomos de los seis de Le antichità di Ercolano esposte, ejemplares conservados hoy en los fondos del Archivo Histórico Provincial de Asturias.

97. CÁNFORA, Luciano. Ideología de los estudios clásicos. Madrid: Akal, 1991, p. 10. Para una filosofía del gusto, véase el estudio clásico, verosímil antecedente de Cánfora en varios aspectos, de Mario Praz Gusto neoclásico (Barcelona: Gustavo Gili, 1982 [1974]), en especial los capítulos «Neoclasicismo e imperio» $\mathrm{y}$ "Clasicismo revolucionario». 
latín y extender la lengua vulgar sería parte de ese proceso. La voluntad literaria de escribir en castellano y convertirlo en un instrumento del mismo nivel que las lenguas clásicas «es un aspecto de la renovación renacentista que no contradice, minusvalora ni suplanta el componente clasicista» ${ }^{98}$. Por eso, sostenía Feijoo en el frontispicio a su magna obra:

Harasme también cargo por qué, habiendo de tocar muchas cosas facultativas, escribo en el idioma castellano. Bastaríame por respuesta el decir que para escribir en el idioma nativo no se ha menester más razón que no tener alguna para hacer lo contrario. No niego que hay verdades que deben ocultarse al vulgo, cuya flaqueza más peligra tal vez en la noticia que en la ignorancia; pero esas ni en latín deben salir al público, pues harto vulgo hay entre los que entienden este idioma, y fácilmente pasan de estos a los que no saben más que el castellano99.

Estas palabras aurorales pueden entenderse con dos voluntades muy distintas. Pero, si las cotejamos con la opinión de Feijoo sobre las lenguas clásicas, la cita no debería utilizarse para denunciar las limitaciones de su desengaño de errores comunes, como si así viniera a reconocer el ocultarle verdades al vulgo. Al contrario, y comoquiera que Feijoo estaba poco dispuesto a recurrir a la lengua del Lacio, estas líneas expresan que su ánimo demótico estuvo más por desvelar que por ocultar, más en la audacia que en la timidez y en hacer que su crítica se extendiera todo lo posible.

Si su corrección de los fueros del latín en la cultura española moderna fue «tema de los delirios» de Feijoo o justo temor ante el obstáculo que oponía a la extensión de la enseñanza y a la educación en las ciencias útiles podría testimoniarlo muchos años después la protesta de Jovellanos en su Memoria sobre educación pública (1802):

La universidad da toda su enseñanza en latín y por autores latinos, y en esta lengua se explica, se diserta, se arguye, se conferencia, y en suma, se habla en ella; porque la lengua latina, por razones que se esconden a mi pobre razón, se ha levantado a la dignidad de único y legal idioma de nuestras escuelas, y lo que es más, se conserva en ellas a despecho de la experiencia y el desengaño ${ }^{100}$.

98. YNDURÁIN, Domingo. «La invención de una lengua clásica. (Literatura vulgar y Renacimiento en España)». En Estudios sobre Renacimiento y Barroco. Madrid: Cátedra, 2006, pp. 83, 85.

99. Feijoo. «Prólogo al lector». En Teatro crítico universal [...], tomo primero. Madrid: Lorenzo Francisco Mojados, 1726, [p. 3].

100. Jovellanos, Gaspar Melchor de. «Memoria sobre educación pública». En Obras completas XIII. Escritos pedagógicos, $1^{\circ}$. Edición crítica, prólogo, estudio introductorio y notas de Olegario Negrín Fajardo. Oviedo: Ayuntamiento de Gijón/Instituto Feijoo de Estudios del Siglo XVIII/Krk Ediciones, 2010, p. 458. 


\section{BiBliografíA}

Aguilar PiÑAl, Francisco. "Entre la escuela y la universidad: la enseñanza secundaria en el siglo XVIII». Revista de Educación, 1988, número extraordinario La educación en la Ilustración española, pp. 225-244.

Alonso Rodríguez, María del Carmen. «La Antigüedad al servicio del rey. La difusión del gusto pompeyano en España en el siglo XVIII. Cuadernos Dieciochistas, 2018, 19, pp. 105-137.

ÁLVAREZ BARRIENTOS, Joaquín. «Para la historia de una amistad: Feijoo (1676-1764) y Sarmiento (1695-1772)». En URZAINQUi, Inmaculada y OlaY VAldÉs, Rodrigo (coords.). Con la razón y la experiencia. Feijoo 250 años después. Oviedo: Instituto Feijoo de Estudios del Siglo XVIII/Universidad de Oviedo/Ediciones Trea, 2016, pp. 489-508.

ÁLVAREZ BARRIENTOS, Joaquín. "Martín Sarmiento (1695-1772), o la escritura como gabinete de curiosidades». En LORENZO Álvarez, Elena de (coord.). Ser autor en la España del siglo XVIII. Gijón: Ediciones Trea, 2017, pp. 83-112.

Ameneiros Rodríguez, Rocío. La biblioteca de Martín Sarmiento: recepción de la Ilustración en España (2015). Universidade da Coruña, Departamento de Humanidades. En línea, Repositorio da Universidade da Coruña, https://ruc.udc.es/dspace/handle/2183/15946 [17/04/2020].

ARDaO, Arturo. La filosofía polémica de Feijoo. Buenos Aires: Losada, 1962.

Bobes, Carmen; BaAmonde, Gloria; Cueto, Magdalena; Frechilla, Emilio y Marful, Inés, Historia de la teoría literaria. I. La Antigüedad grecolatina. Madrid: Gredos, 1995.

[CAmpomanes, Pedro Rodríguez de]. «Noticia de la vida y obra del M. I. y R. P. M. Fr. Benito Jerónimo Feijoo, monje benedictino de la Congregación de España, catedrático de prima de Teología jubilado de la Universidad de Oviedo, maestro general por su Orden, del Consejo de S. M.». En FeIjOo, Benito Jerónimo. Teatro crítico universal, o discursos varios en todo género de materias, para desengaño de errores comunes, tomo primero. Madrid: Imprenta Real de la Gaceta, a costa de la Compañía de Impresores y Libreros del Reino, 1765, pp. I-XLV.

CÁnfora, Luciano. Ideología de los estudios clásicos. Madrid: Akal, 1991.

CoDorniu, Antonio. Dolencias de la crítica, que para precaución de la estudiosa juventud expone a la docta madura edad, y dirige al muy ilustre señor don Fr. Benito Gerónimo Feyjoo, etc. Gerona: Antonio Oliva, 1760.

Constituciones de la Congregación de nuestro glorioso Padre San Benito de España e Inglaterra. Madrid: Viuda de Melchor Álvarez, 1706.

CRISTÓBAl, Vicente. «Los Remedia amoris de Ovidio, en la visión crítica del P. Feijoo». Cuadernos de Filología Clásica: Estudios Latinos, 1991, 1, pp. 233-240.

CurTIUS, Ernst Robert. Literatura europea y Edad Media latina. Trad. Margit Frenk Alatorre y Antonio Alatorre. México: Fondo de Cultura Económica, 1955.

Feijoo, Benito Jerónimo. "Prólogo al lector». En Teatro crítico universal, o discursos varios en todo género de materias, para desengaño de errores comunes [...], tomo primero. Madrid: Lorenzo Francisco Mojados, 1726, [s. p.].

FeIjoo, Benito Jerónimo. «Senectud moral del género humano» (discurso 7). En Teatro crítico universal, o discursos varios en todo género de materias, para desengaño de errores comunes [...], tomo segundo. Madrid: Francisco del Hierro, 1728, pp. 158-178. 
FeIjOO, Benito Jerónimo. "Mapa intelectual y cotejo de naciones» (discurso 15). En Teatro crítico universal, o discursos varios en todo género de materias, para desengaño de errores comunes [...], tomo segundo. Madrid: Francisco del Hierro, 1728, pp. 269-288.

FEIJOO, Benito Jerónimo. "Veritas vindicata adversus medicinam vindicatam». En Teatro crítico universal, o discursos varios en todo género de materias, para desengaño de errores comunes [...], tomo segundo. Madrid: Francisco del Hierro, 1728, pp. 357-384.

FeIjOO, Benito Jerónimo. "La verdad vindicada contra la medicina vindicada. Respuesta apologética traducida de latín en castellano y añadida por el autor». En Teatro crítico universal, o discursos varios en todo género de materias, para desengaño de errores comunes [...], tomo tercero. Madrid: Francisco del Hierro, 1729, pp. 334-366.

FeIjoo, Benito Jerónimo. «Lámparas inextinguibles» (discurso 3). En Teatro crítico universal, o discursos varios en todo género de materias, para desengaño de errores comunes [...], tomo cuarto. Madrid: Viuda de Francisco del Hierro, 1730, pp. 44-63.

FejJoo, Benito Jerónimo. «Mérito y fortuna de Aristóteles y de sus escritos» (discurso 7). En Teatro crítico universal, o discursos varios en todo género de materias, para desengaño de errores comunes [...], tomo cuarto. Madrid: Viuda de Francisco del Hierro, 1730, pp. 127-164.

Feijoo, Benito Jerónimo. «Resurrección de las artes y apología de los antiguos» (discurso 12). En Teatro crítico universal, o discursos varios en todo género de materias, para desengaño de errores comunes [...], tomo cuarto. Madrid: Viuda de Francisco del Hierro, 1730, pp. 280-319.

Feijoo, Benito Jerónimo. «Glorias de España. Parte primera» (discurso 13). En Teatro crítico universal, o discursos varios en todo género de materias, para desengaño de errores comunes [...], tomo cuarto. Madrid: Viuda de Francisco del Hierro, 1730, pp. 320-368.

Feijoo, Benito Jerónimo. «Glorias de España. Segunda parte» (discurso 14). En Teatro crítico universal, o discursos varios en todo género de materias, para desengaño de errores comunes [...], tomo cuarto. Madrid: Viuda de Francisco del Hierro, 1730, pp. 369-422.

FeIjoo, Benito Jerónimo. «Paradojas políticas y morales» (discurso 1). En Teatro crítico universal, o discursos varios en todo género de materias, para desengaño de errores comunes [...], tomo sexto. Madrid: Herederos de Francisco del Hierro, 1734, pp. 1-76.

Feijoo, Benito Jerónimo. «Demoníacos» (discurso 6). En Teatro crítico universal, o discursos varios en todo género de materias, para desengaño de errores comunes [...], tomo octavo. Madrid: Herederos de Francisco del Hierro, 1739, pp. 76-151.

FeIjOO, Benito Jerónimo. "La elocuencia es naturaleza y no arte». En Cartas eruditas y curiosas, en que, por la mayor parte, se continúa el designio del Teatro crítico universal, impugnando o reduciendo a dudosas varias opiniones comunes [...], tomo segundo. Madrid: Herederos de Francisco del Hierro, 1745, pp. 45-56.

FeIJOO, Benito Jerónimo. "Contra la pretendida multitud de hechiceros" (carta 15). En Cartas eruditas y curiosas, en que, por la mayor parte, se continúa el designio del Teatro crítico universal, impugnando o reduciendo a dudosas varias opiniones comunes [...], tomo tercero. Madrid: Herederos de Francisco del Hierro, 1750, pp. 173-181.

FeIjOO, Benito Jerónimo. «Sobre cierta lesión de la vista de un caballero". En Cartas eruditas y curiosas, en que, por la mayor parte, se continúa el designio del Teatro crítico universal, impugnando o reduciendo a dudosas varias opiniones comunes [...], tomo tercero. Madrid: Herederos de Francisco del Hierro, 1750, pp. 182-186.

Feijoo, Benito Jerónimo. "Cómo trata el Demonio a los suyos" (carta 17). En Cartas eruditas y curiosas, en que, por la mayor parte, se continúa el designio del Teatro crítico 
universal, impugnando o reduciendo a dudosas varias opiniones comunes [...], tomo tercero. Madrid: Herederos de Francisco del Hierro, 1750, pp. 187-205.

FeIJOO, Benito Jerónimo. «Sobre el adelantamiento de ciencias y artes en España. Y apología de los escritos del autor» (carta 31). En Cartas eruditas y curiosas, en que, por la mayor parte, se continúa el designio del Teatro crítico universal, impugnando o reduciendo a dudosas varias opiniones comunes [...], tomo tercero. Madrid: Herederos de Francisco del Hierro, 1750, pp. 384-421.

FejJoo, Benito Jerónimo. «Disuade a un amigo suyo el autor el estudio de la lengua griega, y le persuade el de la francesa” (carta 23). En Cartas eruditas y curiosas [...], tomo quinto. Madrid: Joaquín Ibarra, 1760, pp. 374-398.

FeIjOO, Benito Jerónimo. «Reflexiones que sirven a explicar y determinar con más precisión el intento de la inmediata carta antecedente, en la que se sigue última» (carta 24). En Cartas eruditas y curiosas [...], tomo quinto. Madrid: Joaquín Ibarra, 1760, pp. 399-406.

FeIjOO, Benito Jerónimo. "La elocuencia es naturaleza y no arte» (carta 6). En Obras completas III. Cartas eruditas y curiosas [...], tomo II. Ed. Inmaculada Urzainqui, Eduardo San José Vázquez y Rodrigo Olay Valdés. Oviedo: Instituto Feijoo de Estudios del Siglo XVIII/Ayuntamiento de Oviedo/Krk Ediciones, 2018, pp. 90-103.

FilgueIRa VALVERDE, José. «Feijoo y Sarmiento ante la Antigüedad clásica». Cuadernos de la Fundación Pastor, 1983, 1, pp. 9-35.

GIL FERNÁNDEZ, Luis. Campomanes, un helenista en el poder. Madrid: Fundación Universitaria Española, 1976.

GIL FERNÁNDEZ, Luis. Panorama social del humanismo español (1500-1800). Madrid: Alhambra, 1981.

GonzÁlez CALVo, José Manuel. «Latinismos, cultismos». En Creatividad y expresividad en Fray Gerundio de Campazas. Cáceres: Universidad de Extremadura, 2017, pp. 113-159.

Hevia Ballina, Agustín. «Un nuevo acercamiento al padre Feijoo: el catálogo de la librería del monasterio de San Vicente de Oviedo». Studium Ovetense, 1980, VIII, pp. 311-344.

Hevia Ballina, Agustín. "La biblioteca clásica del Padre Feijoo». En VV. AA. II Simposio sobre el Padre Feijoo y su siglo (I). Oviedo: Cátedra Feijoo, 1981, pp. 375-392.

IsLA, José Francisco de. Historia del famoso predicador fray Gerundio de Campazas, alias Zotes. Ed. Joaquín Álvarez Barrientos. Barcelona: Planeta, 1991.

Jovellanos, Gaspar Melchor de. «Memoria sobre educación pública». En Obras completas XIII. Escritos pedagógicos, $1 .^{\circ}$. Edición crítica, prólogo, estudio introductorio y notas de Olegario Negrín Fajardo. Oviedo: Ayuntamiento de Gijón/Instituto Feijoo de Estudios del Siglo XVIII/Krk Ediciones, 2010, pp. 435-532.

LANZ De CaSAFonda, Manuel. Diálogos de Chindulza (Sobre el estado de la cultura española en el reinado del Fernando VI). Oviedo: Cátedra Feijoo/Universidad de Oviedo, 1972.

LAPESA, Rafael. «Sobre el estilo de Feijoo». En VV. AA. Mélanges à la mémoire de Jean Sarrailh, t. II. Paris: Centre de Recherches de l'Institut d'Études Hispaniques, 1966, pp. 21-28.

LÁZARO CARRETER, Fernando. Las ideas lingüísticas en España durante el siglo XVIII. Barcelona: Crítica, 1985.

López Silva, Xosé Antonio. "Feijoo contra los virgilianistas. La polémica sobre Lucano en el siglo XVIII». En García Jurado, Francisco y GonZÁlez González, Marta (eds.). La historia de la literatura grecolatina en España: de la Ilustración al Liberalismo (1778-1850). Málaga: Analecta Malacitana (Anejo XC), 2013, pp. 375-394. 
López VÁzquez, Ramón. O Padre Feixoo, escolástico. Santiago de Compostela: Centro de Investigacións Lingüísticas e Literarias Ramón Piñeiro, 1995.

MarTínez, Martín. "Prólogo». En Medina sceptica y cirugía moderna [...], tomo primero. Madrid: [s. i.], 1722, [s. p.].

MÉNDEZ PlanCarTe, Gabriel. «Introducción». En VV. AA. Humanistas del siglo XVIII. Introd. y selecc. Gabriel Méndez Plancarte. México: Ediciones de la Universidad Nacional Autónoma de México, 1941, pp. VII-XXX.

MenÉNDeZ Pelayo, Marcelino. Historia de las ideas estéticas, III: El siglo XVIII. Madrid: Consejo Superior de Investigaciones Científicas, 1967.

Mestre SANCHIS, Antonio. "Reflexiones sobre el marco político-cultural de la obra del P. Feijoo». Bulletin Hispanique, 1989, 91:2, pp. 295-312.

Mestre SANCHIS, Antonio. Apología y crítica de España en el siglo XVIII. Madrid: Marcial Pons, 2003.

Mestre SANChIS, Antonio. "Científicos y humanistas en la Ilustración española». En AlBeROla-Romá, Armando; Mas GalvaÑ, Cayetano y Die Maculet, Rosario (coords.). Jorge Juan Santacilia en la España de la Ilustración. Sant Vicent del Raspeig: Universitat d'Alacant/Casa de Velázquez, 2015, pp. 19-48.

OlaY VALDÉs, Rodrigo. «Reconstrucción del canon poético en el ensayo de Feijoo». Cuadernos de Estudios del Siglo XVIII, 2013, 23, pp. 151-194.

Praz, Mario. Gusto neoclásico. Barcelona: Editorial Gustavo Gili, 1982.

Regla de nuestro padre san Benito, en latín y romance, con secciones mayores y menores, que para el uso de los que profesan en Hespaña ofrece fray Diego Mecolaeta, de la Congregación de Valladolid. Madrid: Antonio Pérez de Soto, 1751.

RICARD, Robert. «Feijoo et les empereurs romains d'Espagne». En VV. AA. Les empereurs romains d'Espagne (Actes du Colloque International, Madrid 31 mars-6 avril 1964). Paris: Éditions du Centre National de la Recherche Scientifique, 1965, pp. 293-300.

Rodríguez Álvarez, Ramón. La Biblioteca de la Universidad de Oviedo (1765-1934). Oviedo: Universidad de Oviedo, 1993.

RODRíGUEZ ENNES, Luis. La progresiva sustitución del latín universitario por las lenguas vernáculas. Boletín de la Real Academia de la Historia, 2011, 208: I, pp. 31-45.

RODRíGUEZ ENNES, Luis. «Sarmiento, Feijoo y Ortega: una explicación al origen y persistencia histórica de la romanofobia». Revista General de Derecho Romano, 2013, 21.

SARANYANa, José Ignacio. "Sobre el tomismo de Fr. Benito Jerónimo Feijoo». Scripta Theologica: Revista de la Facultad de Teología de la Universidad de Navarra, 1984, 16:1-2, pp. 459-470.

SARMiento, Martín. Sistema de adornos del Palacio Real de Madrid. Ed. Joaquín Álvarez Barrientos y Concha Herrero Carretero. Madrid: Sociedad Estatal España Nuevo Milenio, 2002.

UrZAINQUI, Inmaculada. "Campomanes y su "Noticia" de Feijoo". En MORAles RAYA, Remedios (coord.). Homenaje a la profesora María Dolores Tortosa Linde. Granada: Universidad de Granada, pp. 359-371.

Villa Río, María Palmira. Casal en Oviedo. Estudio documental de los médicos, cirujanos y boticarios de Oviedo en el siglo XVIII. Oviedo: Instituto de Estudios Asturianos, 1967.

YNDURÁrN, Domingo. "La invención de una lengua clásica. (Literatura vulgar y Renacimiento en España)». En Estudios sobre Renacimiento y Barroco. Madrid: Cátedra, 2006, pp. 81-128. 